\title{
Comparison of the Resistance Spot Weldability of AA5754 and AA6022 Aluminum to Steels
}

\author{
Traditional resistance spot welding in combination with a Multi-Ring Domed electrode \\ was used to join two types of aluminum alloys to interstitial-free low carbon steel
}

BY S. HU, A. S. HASELHUHN, Y. MA, Y. LI, B. E. CARLSON, AND Z. LIN

\begin{abstract}
In this paper, a traditional resistance spot welding (RSW) process in combination with a GM-patented Multi-Ring Domed (MRD) electrode was used to join two types of aluminum alloys, AA5754-0 and AA6022-T4, to interstitial-free low carbon steel (LCS). Parallel studies were carried out for AA5754-LCS and AA6022-LCS resistance spot welds to investigate the effects of aluminum contact resistance on the weld profile, interfacial microstructure, defect distribution, and coach peel performance. The results indicated AA5754-0 develops a higher contact resistance when exposed to atmospheric conditions. This resulted in a degradation of the RSW process due to increased internal expulsion of the molten aluminum nugget and concurrent reduction in aluminum nugget size that contributed to a loss in joint mechanical performance. By contrast, AA6022-T4 exhibited a lower contact resistance, which minimized internal expulsion and promoted the retention of larger aluminum nuggets. The larger AA6022 weld nuggets exhibited improved mechanical performance in comparison to the smaller 5754 nuggets.
\end{abstract}

\section{KEYWORDS}

- Resistance Spot Welding • Multi-Ring Domed Electrode - Aluminum Alloy • Oxide Film • Dissimilar Metals

- Intermetallic Compound

\section{Introduction}

The mixed use of metals, such as aluminum alloys joined to steels, has become one trend researched for future vehicle body lightweighting (Ref. 1). To date, the most common solution to join aluminum (Al) alloys and steels are costly mechanical connections, such as self-piercing rivets. Resistance spot welding (RSW) has been demonstrated as a viable technology to join aluminum to aluminum and steel to steel in the automotive industry. This technology is low cost, exhibits high throughput, has a high level of automation, and is adaptable (Refs. 2, 3). Thus, it is advantageous to automo- bile manufacturers to consider using the same process and equipment to weld aluminum to steel. However, the direct joining of aluminum to steel by a traditional RSW process is challenging due to the different physical properties and the metallurgical incompatibility of the two metals as well as the presence of oxide film on the aluminum surface (Ref. 4).

One of the key issues in RSW of Al-steel is the formation of hard and brittle intermetallic compounds (IMCs) at the faying surface, which increase the cracking susceptibility and deteriorate the ductility of the weld (Ref. 4). Existing studies have mostly focused on the characterization of IMC composition and morphology, and its growth kinetics (Refs. 5-11). Rao et al. (Ref. 5) observed two layers of IMCs at the Al-steel faying surface using transmission electron microscopy. The thick $\mathrm{Fe}_{2} \mathrm{Al}_{5}$ phase near the steel side presents a tongue-like morphology, and the thin $\mathrm{FeAl}_{3}$ layer close to the $\mathrm{Al}$ side is serrated and more uniform. Because the $\mathrm{Al}$ and steel are connected by IMCs, the thickness of the IMC layers is believed to be a critical factor influencing the strength of the weld (Ref. 6). Miyamoto et al. (Ref. 7) found the cross tension strength of the weld between $6 \mathrm{xxx}$ series aluminum and low carbon steel (LCS) was $2.0 \mathrm{kN}$ when the IMC thickness was $2 \mu \mathrm{m}$ and strength levels dropped when the IMC thickness increased to $4 \mu \mathrm{m}$. Chen et al. (Ref. 8) confirmed the fracture toughness of the Al-steel faying surface dropped from $1.07 \mathrm{MPa} \mathrm{m}^{1 / 2}$ to $0.35 \mathrm{MPa} \mathrm{m}^{1 / 2}$ when the IMC thickness increased from 3 to $6.5 \mu \mathrm{m}$.

To understand the growth kinetics of the IMC, Yin et al. (Ref. 9) studied the effect of Si content on the growth of the IMC during the reaction between solid iron and molten aluminum. They discovered an obvious reduction of the activation energy of $\mathrm{Fe}_{2} \mathrm{Al}_{5}$ with the increase of $\mathrm{Si}$ content from 0 to $3 \%$, which was attributed to the lattice distortion induced by $\mathrm{Si}$ atoms penetrating into the $\mathrm{Fe}_{2} \mathrm{Al}_{5}$ phase. Hwang et al. (Ref. 10) studied the effect of the Mg content in aluminum alloy on the strength and interfacial microstructure of the Al-Mg alloy/SS400 welds. The results demonstrated the increase of $\mathrm{Mg}$ content from 0 to $3.66 \%$ led to an increase of IMC thickness from 0.7 to $2.9 \mu \mathrm{m}$, which greatly decreased the joint cross tension strength. Shi et al. (Ref. 11) studied the effect of coating type on the microstructure of an Alsteel weld. It was reported that $\mathrm{Ni}$ had a large atomic radius 


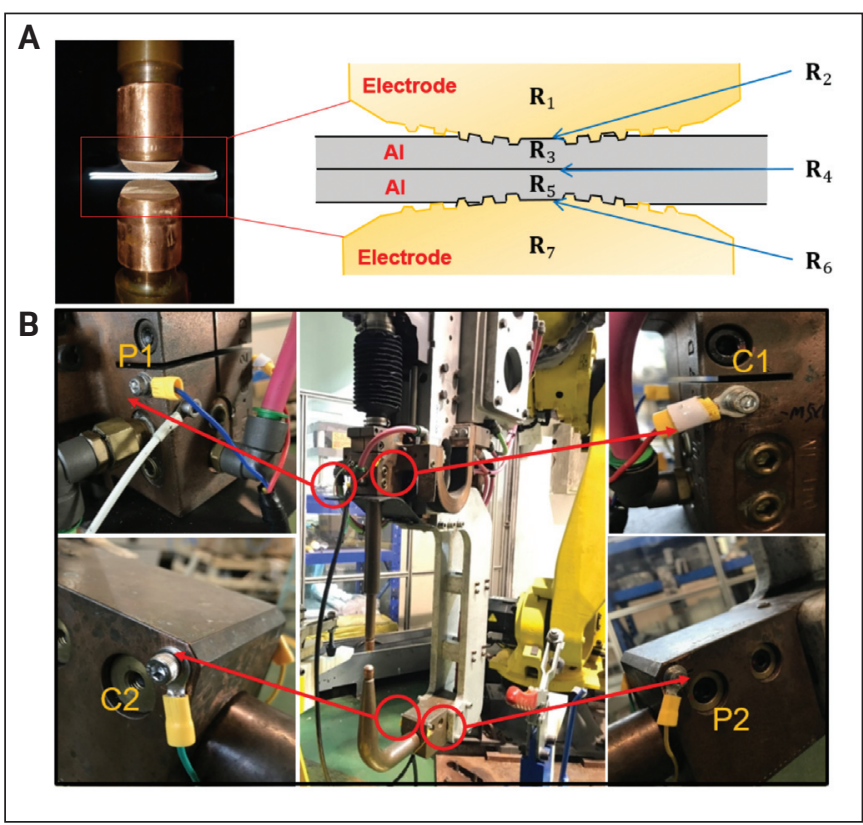

Fig. 1-A - Schematic of the double sheet contact resistance test; $B$ - connection diagram. $\mathrm{Cl}$ and $\mathrm{C} 2$ are the current probes. $P 1$ and $P 2$ are the voltage probes.

and retarded the aluminum diffusion, thus forming a thinner IMC layer. The effect that differences in IMC morphology, IMC thickness, and elemental content have upon RSW joint mechanical performance has not been presented in the literature.

To date, aluminum alloys such as nonheat-treatable $5 \mathrm{xxx}$ series Al-Mg alloys and heat-treatable 6xxx series Al-Mg-Si alloys have been widely used in different automobile structures (Ref. 12). Oxide film on the aluminum surface produced during the transportation and storage of aluminum alloy parts has a nonuniform distribution, which complicates the heat generation in and around the weld, and raises the variability in weld quality (Ref. 13).

In the more standard Al-Al RSW process, thick oxide films on the sheet significantly increase electrical contact resistance at both the sheet-electrode and sheet-sheet interfaces, which generates excessive heat according to Joule's law (Ref. 14) and increases the risk of expulsion. The presence of oxide film, particularly at the sheet-sheet interface, is helpful to nucleate and grow the aluminum nugget by concentrating heat in the weld region and counteracting the high heat dissipation rate of the aluminum alloy (Ref. 15). However, the oxide film at the electrode-sheet interface generates excessive heat around the electrode due to high contact resistance, which results in surface expulsion, electrode wear, and poor weld consistency. Zhang et al. (Ref. 16) indicated that the nonuniform $\mathrm{Al}_{2} \mathrm{O}_{3}$ layer on the aluminum sheets produced localized heating between the $\mathrm{Cu}$ electrode and $\mathrm{Al}$ workpiece, which accelerated alloying between $\mathrm{Cu}$ and $\mathrm{Al}$ and deteriorated the electrode face. Li et al. (Ref. 17) compared the electrode life of welding 5A02 aluminum sheets with four different surface conditions - namely, untreated, chemically cleaned, degreased, and electric-arc cleaned - and found the chemically cleaned sheets with the thinnest and the most uniform layer of $\mathrm{Al}_{2} \mathrm{O}_{3}$ could produce
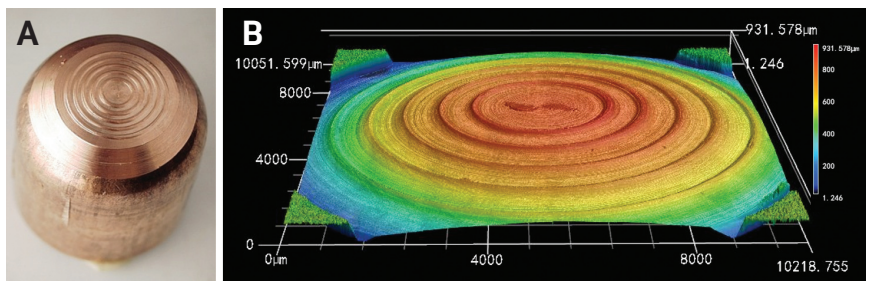

Fig. 2 - MRD electrode: A - Physical image; B - weld face morphology scanned by KEYENCE VHX-2000 digital imaging system.

more than 2300 welds with consistent shear strength while the electrode life of welding untreated sheets was only about 200 welds. Many studies have explored methods to mitigate the negative effects of oxide films (Refs. 15, 18-22). Ihsan et al. (Ref. 18) studied the effect of aluminum surface pretreatment on the RSW quality of AA1050 aluminum alloy by either alkaline washing the aluminum surfaces in $\mathrm{NaOH}$ or by glass blasting the oxide, and indicated that glass blasting removed the original oxide film by plastic deformation, which reduced the contact resistance and improved the weld quality. Arrington (Ref. 19) removed the oxide film on the aluminum surface by twisting the electrode before welding and demonstrated significant improvement in the welding stability. While effective, these pretreatment methods require additional steps prior to the welding process, leading to increased process costs and longer cycle times which are undesirable in a manufacturing environment.

A new electrode design featuring a plurality of raised concentric rings, the GM-patented Multi-Ring Domed (MRD) electrode, has been demonstrated as an effective solution to break oxide films and enable direct welding of aluminum alloys without the use of pretreatment steps (Refs. 20-22). The raised concentric rings create micromechanical regions of tension and compression, which break apart oxide films when the electrodes are pressed into the sheet metal. This reduces the electrode-sheet contact resistance and focuses heat at the sheet-sheet faying interface to form an aluminum weld nugget. It has been demonstrated experimentally that aluminum welds made with the MRD electrode exhibit improved mechanical performance compared to those with a sandblast textured surface (Ref. 15).

The RSW process using MRD electrodes was also successfully used to weld aluminum to steel (Ref. 4). In addition to the MRD electrodes, multiple solidification weld schedules were used to repeatedly heat and cool the weld nugget, which drove defects toward the center of the weld where they did not impact weld strength (Ref. 4). Many studies have been presented to demonstrate welding 6xxx directly to steel using this process, including fatigue behavior (Refs. 5,23 ), influence of steel coatings (Ref. 11), and robustness to simulated production conditions (Refs. 24, 25). Similar work has not been presented for $5 \mathrm{xxx}$ aluminum directly welded to steel using the same MRD electrode and multiple solidification weld schedules.

Thus, the objective of the current study is to compare 5754 steel welds to those of 6022 steel welds to understand their fundamental similarities and differences. Specifically, prior literature has demonstrated that $5 \mathrm{xxx}$ and $6 \mathrm{xxx}$ alloys exhibit different oxide film behavior, which may affect the 
Table 1 - Chemical Compositions of AA5754-0, AA6022-T4, and HDG LCS (wt-\%)

\begin{tabular}{|c|c|c|c|c|c|c|c|c|}
\hline Material & $\mathrm{Si}$ & $\mathrm{Cu}$ & $\mathrm{Mg}$ & $\mathrm{Fe}$ & $\mathrm{Mn}$ & $\mathrm{Zn}$ & $\mathrm{Ti}$ & $\mathrm{Al}$ \\
\hline AA5754-0 & 0.12 & 0.02 & 2.70 & 0.28 & 0.11 & 0.01 & 0.01 & Bal. \\
\hline AA6022-T4 & 0.83 & 0.06 & 0.60 & 0.11 & 0.07 & 0.003 & 0.003 & Bal. \\
\hline HDG LCS & 0.003 & 0.11 & 0.01 & 0.008 & 0.005 & 0.034 & Bal. & - \\
\hline
\end{tabular}

Table 2 - Mechanical Properties of AA5754-0, AA6022-T4, and HDG LCS

\begin{tabular}{ccccc} 
Material & Ultimate Tensile Strength $(\mathrm{MPa})$ & Yield Strength $(\mathrm{MPa})$ & Elongation $(\%)$ & Coefficient of Thermal Expansion $\left(\times 10^{-6} \mathrm{~K}^{-1}\right)$ \\
\hline AA5754-0 & 229.7 & 91.6 & 14.60 & 25.73 \\
AA6022-T4 & 282.4 & 171.8 & 26.67 & 25.84 \\
HDG LCS & 275.0 & 138.0 & 60.70 & 15.05 \\
\hline
\end{tabular}

Table 3- Multiple Solidification Weld Schedules

\begin{tabular}{ccccc} 
Stack-Up & Weld Force & Preheat & Stage 1 (RMS) & Stage 2 (RMS) \\
\hline $5754-H D G ~ L C S$ & $1200 \mathrm{lb}(5.34 \mathrm{kN})$ & $40 \mathrm{~ms} @ 8 \mathrm{kA}, 10 \mathrm{~ms} \mathrm{cool}$ & $250 \mathrm{~ms} @ 9.3 \mathrm{kA}, 500 \mathrm{~ms} \mathrm{c00l}$ & $1420 \mathrm{~ms} @ 11.3 \mathrm{kA}$ \\
\hline $6022-\mathrm{HDG}$ LCS & $800 \mathrm{lb}(3.56 \mathrm{kN})$ & $40 \mathrm{~ms} @ 6 \mathrm{kA}, 10 \mathrm{~ms} \mathrm{cool}$ & $680 \mathrm{~ms} @ 12 \mathrm{kA}, 100 \mathrm{~ms} \mathrm{cool}$ & $1125 \mathrm{~ms} @ 12.7 \mathrm{kA}$ \\
\hline
\end{tabular}

direct weldability of aluminum to steel. Commercial automotive-grade aluminum alloys AA5754-O and AA6022-T4 were compared in both the as-received surface condition, which exhibited a high contact resistance, and the deoxidized surface condition. Parallel experiments were performed to directly weld these aluminum alloys to hot-dipped galvanized (HDG) LCS using MRD electrodes and multiple solidification weld schedules. The resultant Al-steel welds were evaluated in regards to metallographic geometry, IMC properties, defect distribution, and coach peel performance.

\section{Experimental Procedures}

\section{Materials}

The materials used in this study were 1.0 -mm-thick aluminum alloy AA5754-O, 1.2-mm-thick aluminum alloy AA6022-T4, and 2.0-mm-thick HDG LCS sheets. The chemical compositions of the materials are summarized in Table 1. Mechanical properties of these sheet materials were obtained from standard tensile tests, and their corresponding coefficients of thermal expansion were measured using a thermal expansion instrument (DIL 402 Expedis) (see Table 2).

To create variations in sheet contact resistance by growing the oxide film on the aluminum sheet surfaces, the asreceived 5754 and 6022 sheets were treated with two different methods. One method exposed the as-received aluminum alloy sheets in ambient conditions in Shanghai, China, for one year without any additional protection to grow the aluminum oxide film on the sheet surface (hereafter referred to as "oxidized" sheets). In the second method, the aluminum sheets were pretreated by alkaline washing and pickling immediately prior to welding to remove the surface oxide film (hereafter referred to as "clean" sheets).
The thickness of the oxide film and its distribution on the aluminum surface can be difficult to directly measure. While careful analysis in a scanning electron microscope (SEM) can reveal the oxide film thickness, an electrical contact resistance test is an easy method used to indirectly evaluate the oxidation state on the aluminum surface. Figure 1 shows the schematic of the double sheet contact resistance test.

Single and double sheet contact resistance tests were performed, respectively. One or two aluminum sheets from the same grade and surface condition were placed in a servohydraulic welding gun designed for spot welding aluminum and equipped with MRD welding electrodes. An electrode clamping force of $700 \mathrm{lb}(3111 \mathrm{~N})$ was applied with a holding time of $10 \mathrm{~s}$. Under this force, the three inner rings of the MRD electrode were embedded in the aluminum sheets. This broke apart the oxide film at the electrode-sheet interface and resulted in intimate contact between the electrode and the sheet. Then, the resistance between the two electrodes was measured using a micro-ohmmeter with four terminals attached to the two electrodes (see Fig. 1B), at an output current of $10 \mathrm{~A}$.

For the test comprised of two sheets, the total measured resistance $R_{\text {double }}$ is comprised of the bulk resistance of the two copper electrodes $\left(R_{1}\right.$ and $\left.R_{7}\right)$, the bulk resistance of the two aluminum sheets $\left(R_{3}\right.$ and $\left.R_{5}\right)$, and the contact resistance at the three surfaces $\left(R_{2}, R_{4}\right.$, and $\left.R_{6}\right)$, where $R_{4}$ directly indicates the aluminum surface condition - Fig. 1, i.e.,

$$
\mathrm{R}_{\text {double }}=\mathrm{R}_{1}+\mathrm{R}_{2}+\mathrm{R}_{3}+\mathrm{R}_{4}+\mathrm{R}_{5}+\mathrm{R}_{6}+\mathrm{R}_{7}
$$

For the single sheet test, the total measured contact resistance $R_{\text {single }}$ includes the bulk resistance of the two copper electrodes $\left(R_{1}\right.$ and $\left.R_{7}\right)$, the bulk resistance of one aluminum 


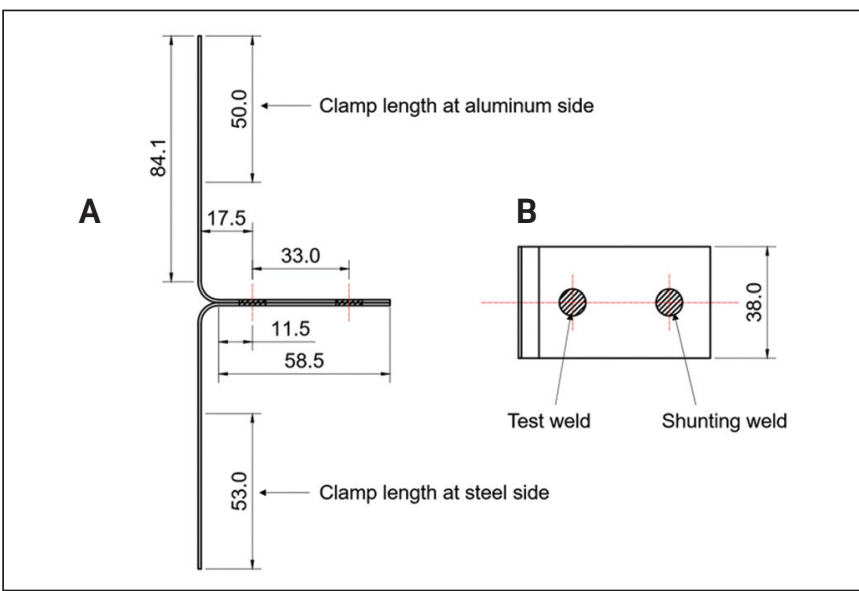

Fig. 3 - Dimensions of the coach peel specimen. A - Main view; $B$ - top view. (Unit: $\mathrm{mm}$ )

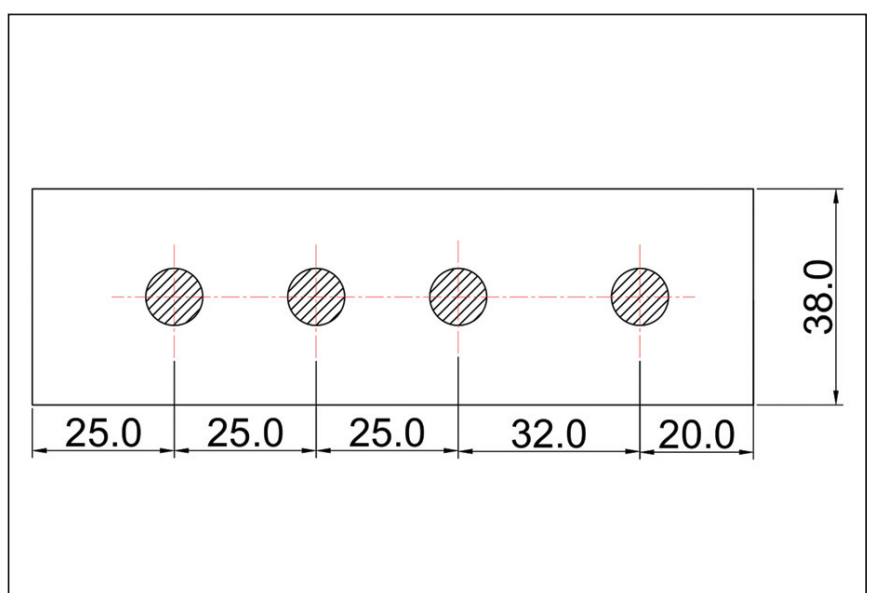

Fig. 4 - Dimensions of the metallographic specimen. (Unit: $\mathrm{mm}$ )

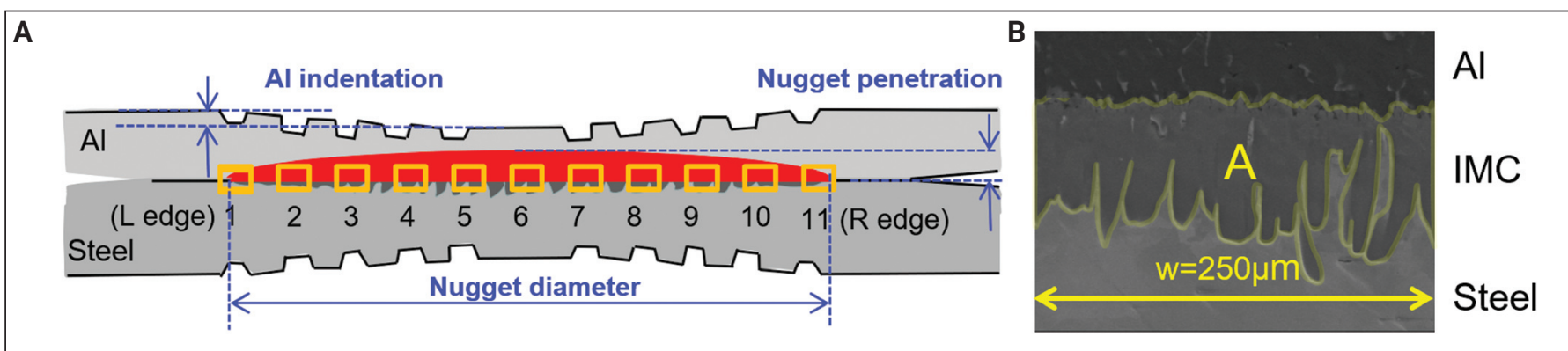

Fig. 5 - Illustrations of metallurgical examinations: A - Definitions of different weld dimensions and locations of IMC thickness measurement regions; $B-$ calculation method of IMC thickness.

sheet $\left(R_{3}\right)$, and the contact resistance at the two surfaces $\left(R_{2}\right.$ and $\mathrm{R}_{6}$ ), i.e,

$$
\mathrm{R}_{\text {single }}=\mathrm{R}_{1}+\mathrm{R}_{2}+\mathrm{R}_{3}+\mathrm{R}_{6}+\mathrm{R}_{7}
$$

Because the contact resistance between the two aluminum sheets $\mathrm{R}_{4}$ is much larger than the bulk resistances of aluminum sheet $\mathrm{R}_{5}, \mathrm{R}_{4}$ can be calculated as follows:

$$
\mathrm{R}_{4}=\mathrm{R}_{\text {double }}-\mathrm{R}_{\text {single }}-\mathrm{R}_{5} \approx \mathrm{R}_{\text {double }}-\mathrm{R}_{\text {single }}
$$

For each of the four types of aluminum sheets, 30 repetitive measurements were performed on different locations of the single and double sheets; the averaged resistance and the standard deviation were calculated.

\section{Experimental Setup and Welding Schedules}

The welding system was comprised of a CenterLine medium frequency direct current weld gun designed for spot welding aluminum mounted on a FANUC R-2000i industry robot, with a 6043 WTC programmable logic controller. The weld gun has a maximum output current of $55 \mathrm{kA}$ and a maximum electrode force of $910 \mathrm{kN}$. The movable and stationary shanks of the weld gun are the positive and negative electrodes, respectively. All the welds were made with the aluminum sheet contacting the positive electrode and steel sheet contacting the negative electrode. The flow rate of the cooling water was $6 \mathrm{~L} / \mathrm{min}$ for each shank.

The MRD electrodes were conventional C15000 with a body diameter of $19.05 \mathrm{~mm}$. A rotary cutting blade was used to create the ringed profile of the MRD electrode; no spinning of the weld gun was used to produce this geometry (Ref. 26). The MRD electrode in this study featured a $25-\mathrm{mm}$ radius of curvature surface with five concentric rings. The average ring heights of the as-dressed MRD electrodes were measured to be 75.2, 92.8, 84.2, 55.5, and 51.9 $\mu \mathrm{m}$, respectively, from inner to outer ring using a KEYENCE VHX-2000 digital imaging system, as shown in Fig. 2.

The proprietary multiple solidification weld schedules developed in this study were designed to produce button pullout fracture in the aluminum sheet (Refs. 27, 28). Different schedules were developed for 5754-HDG LCS and 6022HDG LCS to accommodate differences in alloy and sheet thickness (Table 3).

The 6022-HDG LCS schedule inputs more heat into the stack-up with the two distinct weld stages and the lower weld force to generate the targeted nugget size for the thicker aluminum. All sheets were cleaned by ethanol prior to welding. Samples were welded in a nonconductive fixture to produce welds in the same location on every test specimen. Coach peel tests were performed for the Al-steel welds in this study. Figure 3 provides the dimensions of the coach peel sample, which is comprised of two welds. The weld near the coach peel bend is the test weld, which was pulled to fracture during the coach peel test. The other weld is the 

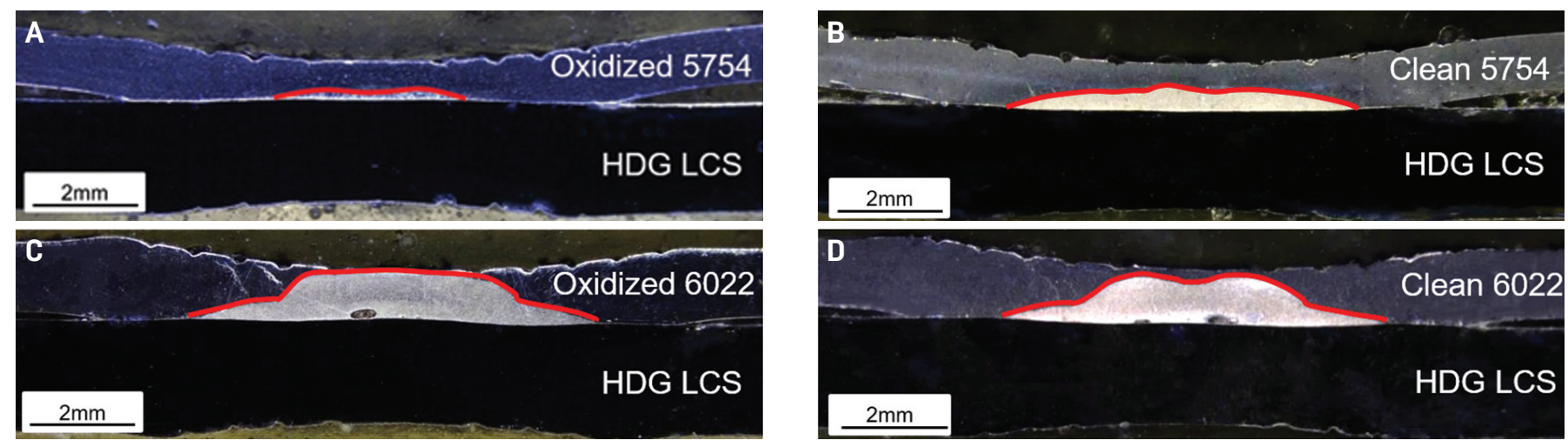

Fig. 6 - Morphologies of the Al-steel welds. A - Oxidized 5754-HDG LCS; B - clean 5754-HDG LCS; C - oxidized 6022-HDG LCS; D- clean 6022-HDG LCS.

shunt weld, which was welded before the test weld to anchor the metal sheets and was not destroyed during testing. Seven coach peel specimens and a single metallurgical test coupon were welded for each stack-up — Figs. 3 and 4.

\section{Metallurgical Examination}

For metallurgical analysis of the weld, the RSW specimens were sectioned along the weld center, cold mounted in epoxy, and polished to a surface finish of $0.03 \mu \mathrm{m}$ using silica polishing media. Three samples per stack-up were used for metallographic analysis. The IMC layers between aluminum and steel were imaged on the nonetched samples using a Leica DM4 M digital optical microscope. IMC thickness distribution was measured manually at 11 evenly distributed regions across each weld - Fig. 5A. The average IMC thickness in each of the 11 regions was calculated as follows:

$$
t=A / w
$$

where $t$ is the average IMC thickness in this region, $A$ is the area enclosed by the Al/IMC and IMC/steel boundary lines, and $w$ is the width of the region that was fixed at $250 \mu \mathrm{m}$ - Fig. 5B.

Finer scale observations of the microstructure and IMC morphology in the Al-steel welds were conducted on a JEOL SEM. To identify the IMC composition in the Al-steel welds, energy dispersive spectroscopy (EDS) spot scan was performed at an acceleration voltage of $15 \mathrm{keV}$.

Following this, the polished samples were etched using Keller's reagent to reveal the aluminum microstructure. A Leica digital optical microscope S8 APO was used to image the macro profiles of the weld and fractographies under low magnification. The weld dimensions, including aluminum nugget diameter at the faying interface, aluminum indentation, and nugget penetration in the weld center were measured Fig. 5A. Three specimens were measured to obtain an average value for each dimension, as well as the standard deviation.

\section{Mechanical Testing}

Quasi-static tests were performed on a SUNS tensile machine by fixing the steel sheet and pulling the aluminum sheet side at a rate of $5.0 \mathrm{~mm} / \mathrm{min}$. Seven coupons were re-
Table 4- Contact Resistance of AA5754-0 and AA6022-T4 Aluminum Alloy Sheets $(\mu \Omega)$

\begin{tabular}{lcccc} 
& $\begin{array}{c}\text { Oxidized } \\
5754-0\end{array}$ & $\begin{array}{c}\text { Clean } \\
5754-0\end{array}$ & $\begin{array}{c}\text { Oxidized } \\
6022-\mathrm{T} 4\end{array}$ & $\begin{array}{c}\text { Clean } \\
6022-\mathrm{T} 4\end{array}$ \\
\hline $\mathrm{R}_{\text {double }}$ & 1807.10 & 48.97 & 228.37 & 108.53 \\
$\mathrm{R}_{\text {single }}$ & 125.50 & 34.00 & 37.00 & 36.00 \\
$\mathrm{R}_{4}$ & 1681.60 & 14.97 & 191.37 & 72.53 \\
\hline
\end{tabular}

peated for each condition. For each fractured sample, a Vernier caliper was used to measure the weld button size after fracture. The button size was calculated as the average of the minimum and the maximum width values measured along the circumference direction of the button.

\section{Results and Discussion}

\section{Aluminum Sheet Contact Resistance}

The oxidized sheets demonstrated a much higher resistance than the clean ones, and the 5754 sheets showed a higher order of resistance than the 6022 sheets, indicating a much thicker oxide film may have formed on the 5754 surface (Table 4). This is because the 5754-O contains a larger amount of $\mathrm{Mg}$ than the 6022-T4. Mg has a greater affinity for oxygen than $\mathrm{Al}$, meaning $5754-\mathrm{O}$ is oxidized more easily to form $\mathrm{MgO} . \mathrm{MgO}$ is less dense than other oxides formed on a metal surface, such as $\mathrm{Al}_{2} \mathrm{O}_{3}$, and leaves the magnesium surface exposed, which can continue to react with the atmosphere to further oxidize (Ref. 29). In contrast, on a 6022-T4 sheet, the dense $\mathrm{Al}_{2} \mathrm{O}_{3}$ film does not exhibit fractures that expose the parent metal, thus preventing further oxidation on the surface (Refs. 29, 30).

\section{Weld Morphology}

In traditional, similar metal spot welds, such as $\mathrm{Al}-\mathrm{Al}$ and steel-steel, a portion of the faying surface between the metal sheets is eliminated due to melting when current passes through, resulting in a relatively symmetric nugget comprised of material from two or more sheets. However, in dissimilar Al-steel RSW, there is typically a nugget in the aluminum sheet that directionally solidifies against the steel 

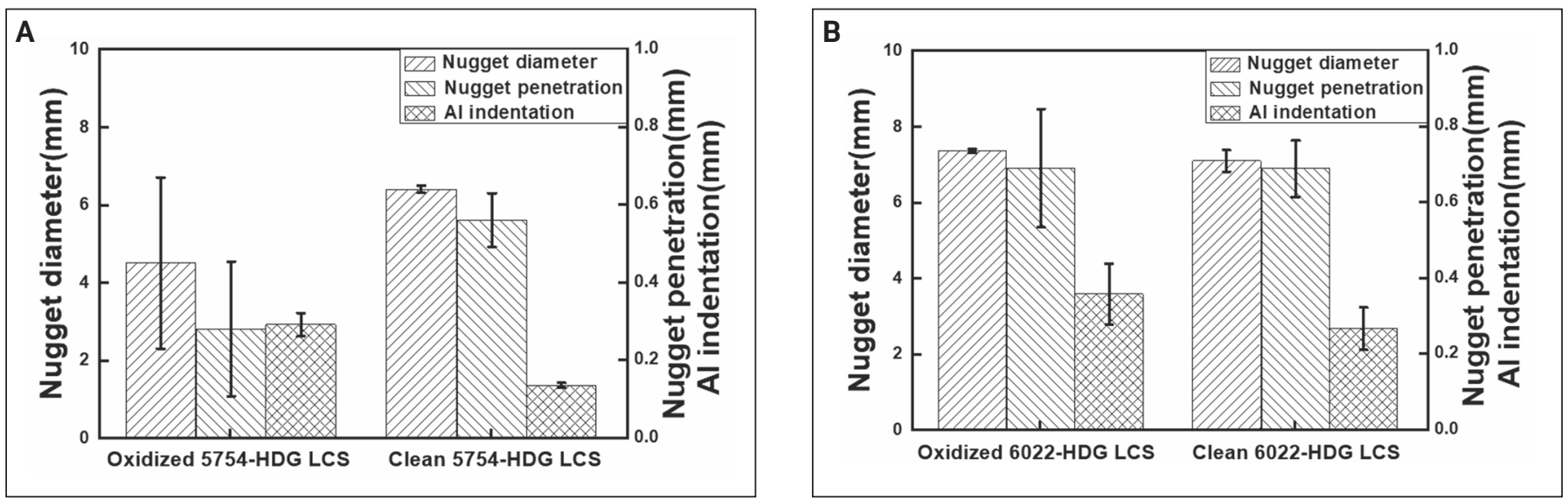

Fig. 7-Measured nugget diameter, aluminum indentation, and nugget penetration of the Al-steel welds: A - 5754-HDG LCS; B 6022-HDG LCS. Error bars represent \pm 1 standard deviation.
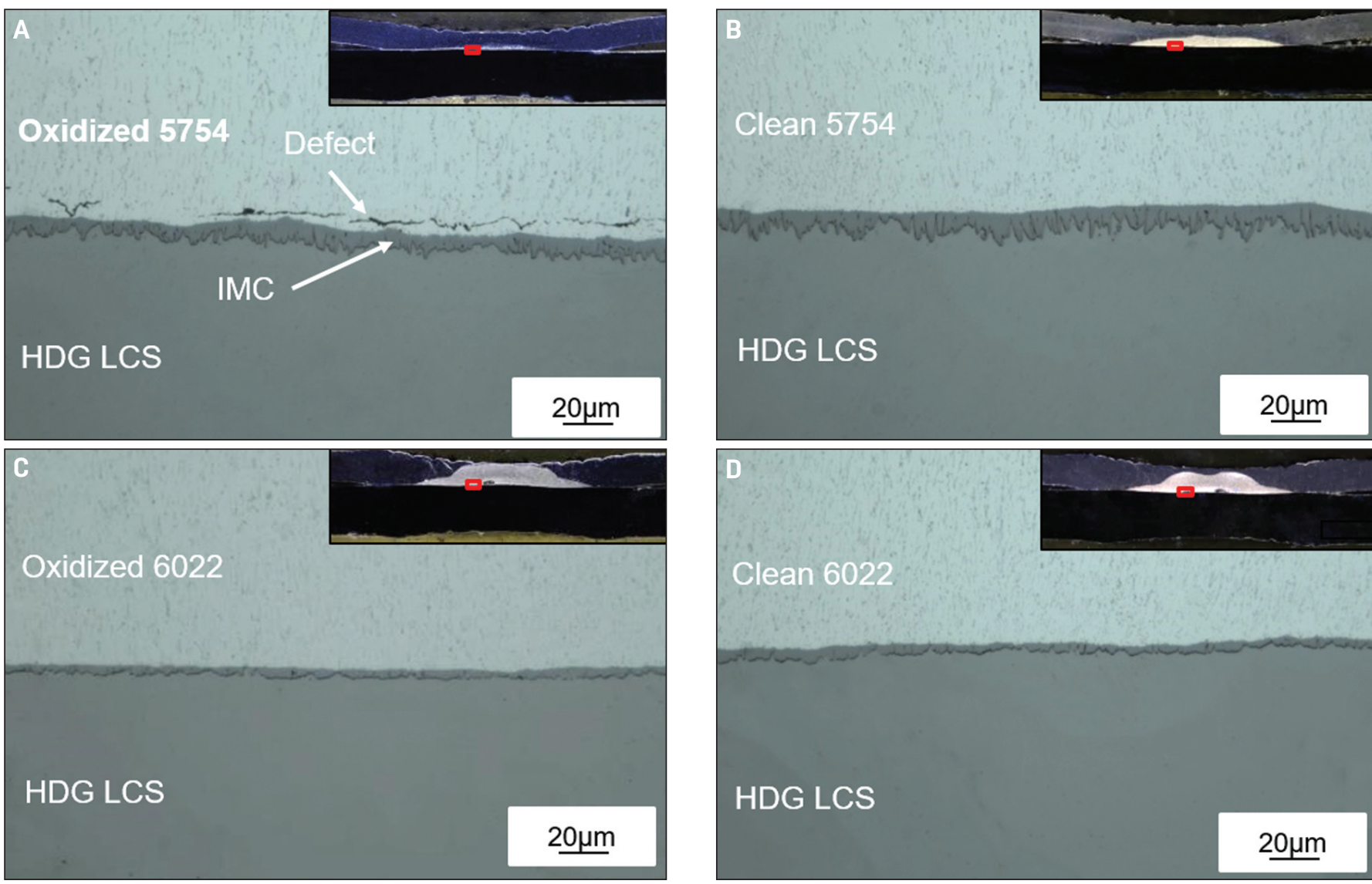

\section{HDG LCS}
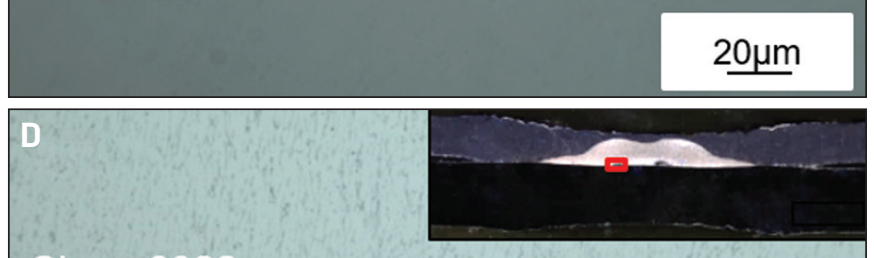

\section{Clean 6022}

\section{HDG LCS}

\section{$20 \mu \underline{m}$}

Fig. 8- Oxide film defects observation on the faying surface of Al-steel welds. A - Oxidized 5754 sheet; B - clean 5754 sheet; C - oxidized 6022 sheet; D - clean 6022 sheet.

sheet, creating an asymmetric weld. There is no melting and mixing of the steel sheet with the aluminum sheet at the faying interface. Figure 6 shows the weld morphologies for both the oxidized and clean sheets of 5754 and 6022 welded to HDG LCS. In all the welds, a nugget formed on the Al side starting from the faying interface, and the Al sheets showed obvious indentations. The weld of oxidized 5754-HDG LCS exhibited the smallest nugget size, as shown in Fig. 6A, while the other welds formed much larger crescent-shaped nuggets, as shown in Fig. 6B-D.
Figure 7 compares the measured values of the aluminum nugget diameter, the aluminum indentation, and the nugget penetration in the center of the four welds. The oxidized 5754-HDG LCS welds exhibited a smaller nugget diameter, and smaller nugget penetration, but a larger $\mathrm{Al}$ indentation than the clean welds, which was caused by significant internal expulsion of the molten aluminum weld pool. However, for the 6022 welds, the clean and oxidized welds did not exhibit significant geometrical differences.

It should be noted that two of the three oxidized 5754- 


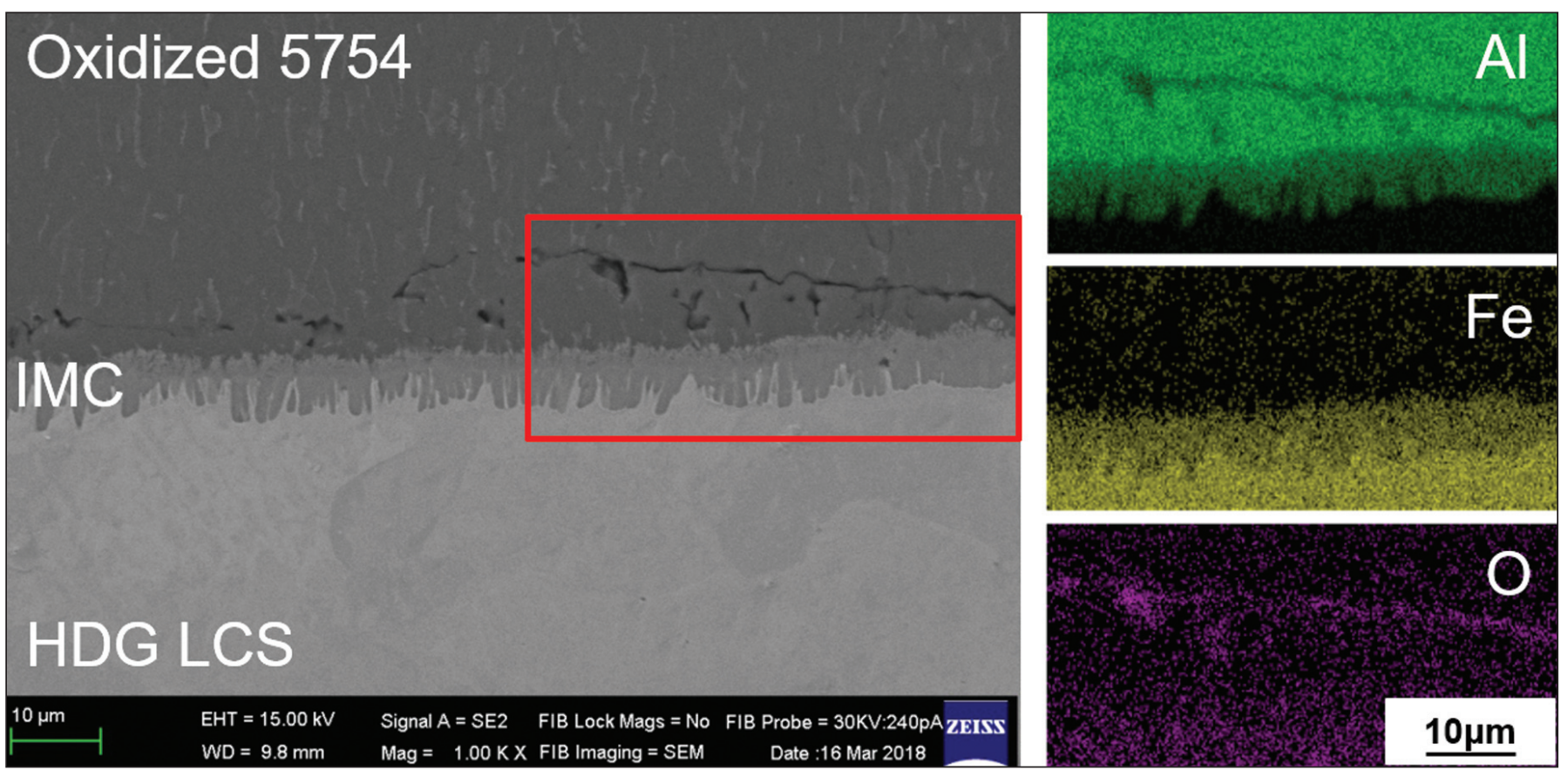

Fig. 9-EDS mapping of the defects in Fig. 8A.

\begin{tabular}{|c|c|c|c|c|c|c|c|}
\hline Stack-up & Spot & $\mathrm{Al}$ & $\mathrm{Fe}$ & $\mathrm{Mg}$ & $\mathrm{Si}$ & Al:Fe & Anticipated Phase \\
\hline \multirow{2}{*}{ 5754-HDG LCS } & 1 & 56.46 & 41.52 & 0.55 & 0.00 & 1.36 & $\mathrm{FeAl}_{3}$ \\
\hline & 3 & 46.00 & 52.65 & 0.00 & 0.00 & 0.87 & $\mathrm{Fe}_{2} \mathrm{Al}_{5}$ \\
\hline \multirow[b]{2}{*}{ 6022-HDG LCS } & 4 & 62.24 & 35.62 & 0.25 & 0.06 & 1.74 & $\mathrm{FeAl}_{3}$ \\
\hline & 5 & 46.80 & 51.51 & 0.00 & 0.25 & 0.91 & $\mathrm{Fe}_{2} \mathrm{Al}_{5}$ \\
\hline
\end{tabular}

HDG LCS specimens exhibited internal expulsion, in which a portion of the molten aluminum nugget rapidly escaped from the molten weld pool and solidified against the sheet metal at the faying interface in the peripheral area surrounding the weld nugget (Ref. 24). The oxidized 5754 sheet exhibited a high contact resistance, as shown in Table 4. During welding, the high contact resistance caused excessive heat generation at the Al-steel faying surface, and produced a relatively large weld pool. Internal expulsion removed both heat and molten aluminum from the weld pool. This loss of metal produced a smaller nugget, thinned the weld structure, and also produced large deviations in nugget diameter and nugget penetration. The presence of expulsion in two of the three welds also indicated the oxide film on the oxidized 5754 was inconsistent. For the clean 5754 sheet with lower contact resistance, no internal expulsion occurred and a much larger nugget size was observed.

For both the clean and oxidized sheets of 6022, contact resistances were comparatively low and no expulsion was observed in the 6022-HDG LCS welds. Compared to the clean 6022 welds, the oxidized welds exhibited a slightly higher contact resistance, which provided extra heat to help grow the nugget and to form a somewhat larger nugget diameter.

\section{Weld Defects}

Differences were also observed at the faying interface of clean vs. oxidized 5754-HDG LCS and 6022-HDG LCS welds - Fig. 8.

Semicontinuous black lines were observed across the faying interface of the oxidized 5754 aluminum above the IMC layer. The clean 5754 aluminum and both clean and oxidized 6022containing welds only exhibited this microstructural feature at the weld nugget edges. Rather than a crack, Sigler et al. (Ref. 4) previously identified this defect as an oxide film using electron probe microanalysis. Energy dispersive spectroscopy surface mapping was performed to identify the defects, as shown in Fig. 9. In the scanned region, oxygen accumulated at the defects, confirming the presence of oxide film along the faying surface. Oxides melt at a much higher temperature than their pure metal counterparts. Thus, during the RSW process, the oxide film at the faying surface does not melt. Rather, it is broken into smaller oxide particles and dissolves into the aluminum nugget or it remains near the faying interface acting as a low-energy crack path (Ref. 4).

In addition to the oxide films, porosity was observed in the middle of the aluminum nugget, near the faying interface in welds comprised of oxidized 5754, oxidized 6022, 

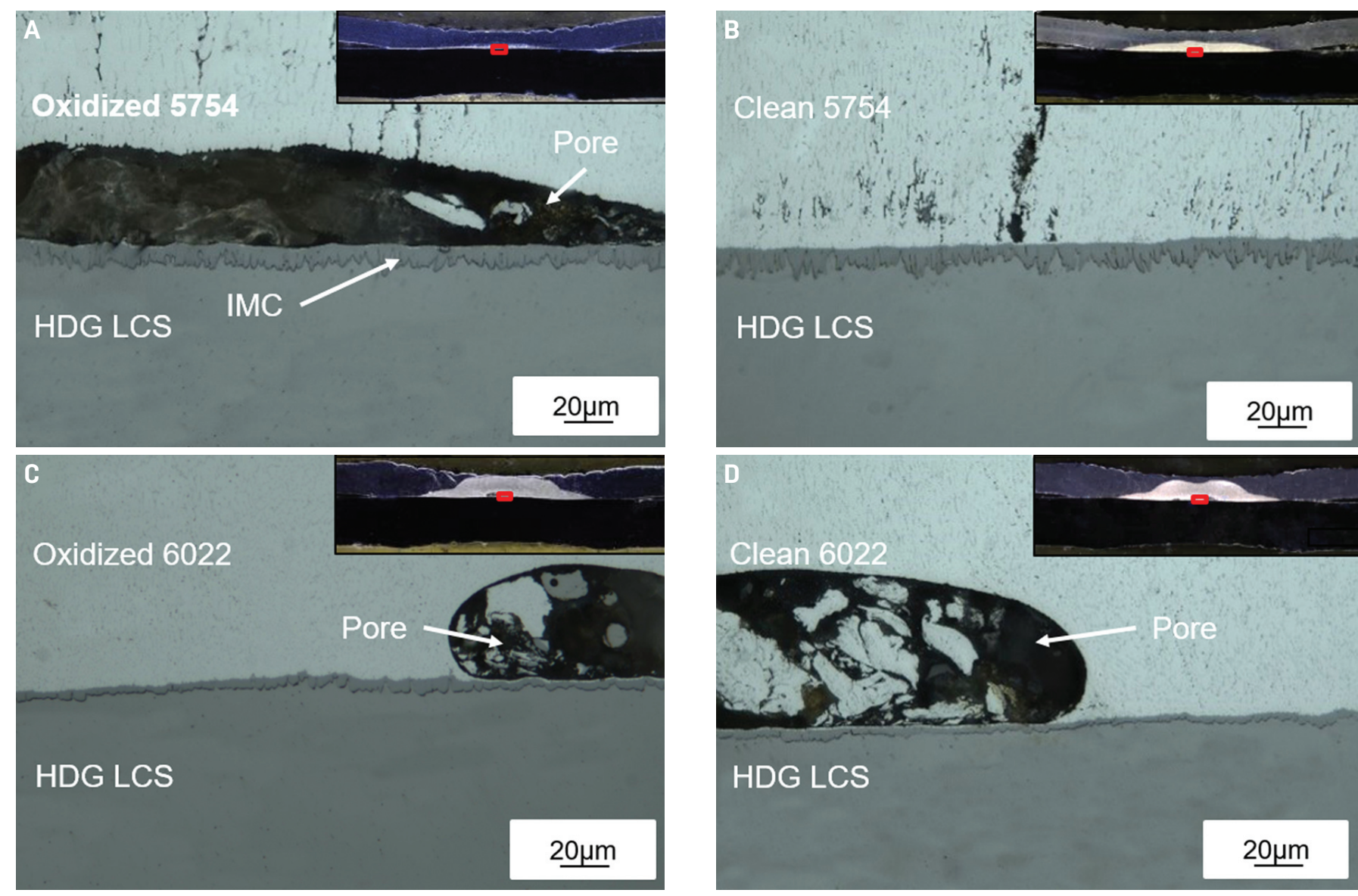

\section{HDG LCS}
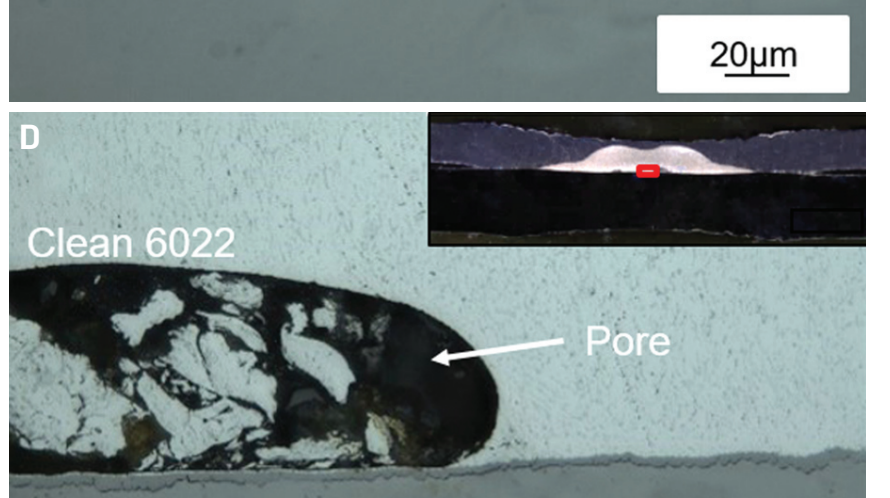

\section{HDG LCS}

Fig. 10 - Pore defects at the faying surface. A - Oxidized 5754 sheet; B - clean 5754 sheet; C - oxidized 6022 sheet; D - clean 6022 sheet.
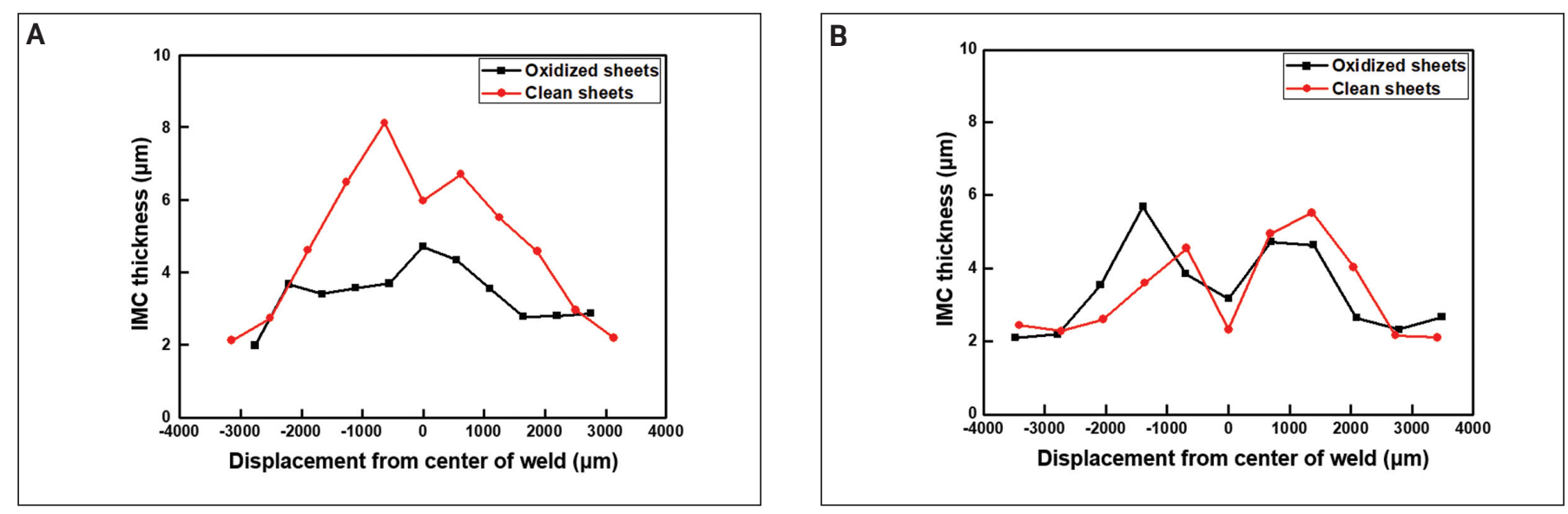

Fig. 11 - IMC thickness distribution along the faying surface of Al-steel welds. A - Oxidized and clean 5754-HDG LCS; B - oxidized and clean 6022-HDG LCS.

and clean 6022. In contrast, shrinkage porosity was observed in the clean 5754 weld - Fig. 10. Oxide films on aluminum sheets are known to absorb water, which may have facilitated the formation of pores after welding (Ref. 32).

\section{IMC Characteristics}

In dissimilar $\mathrm{Al}$-steel spot welds, $\mathrm{Fe}_{\mathrm{x}} \mathrm{Al}_{\mathrm{y}} \mathrm{IMC}$ layers at the faying surface serve as the bond between the two metals. The thickness and distribution of the IMC layers are sensitive to the Joule heat generation and can significantly influence the mechanical performance of the weld. Figure 11 gives the measured IMC thickness distributions of the four types of welds.

At the left and right edges of the nugget, all welds exhibited thin IMC layers, with the thickness close to $2.0 \mu \mathrm{m}$. 

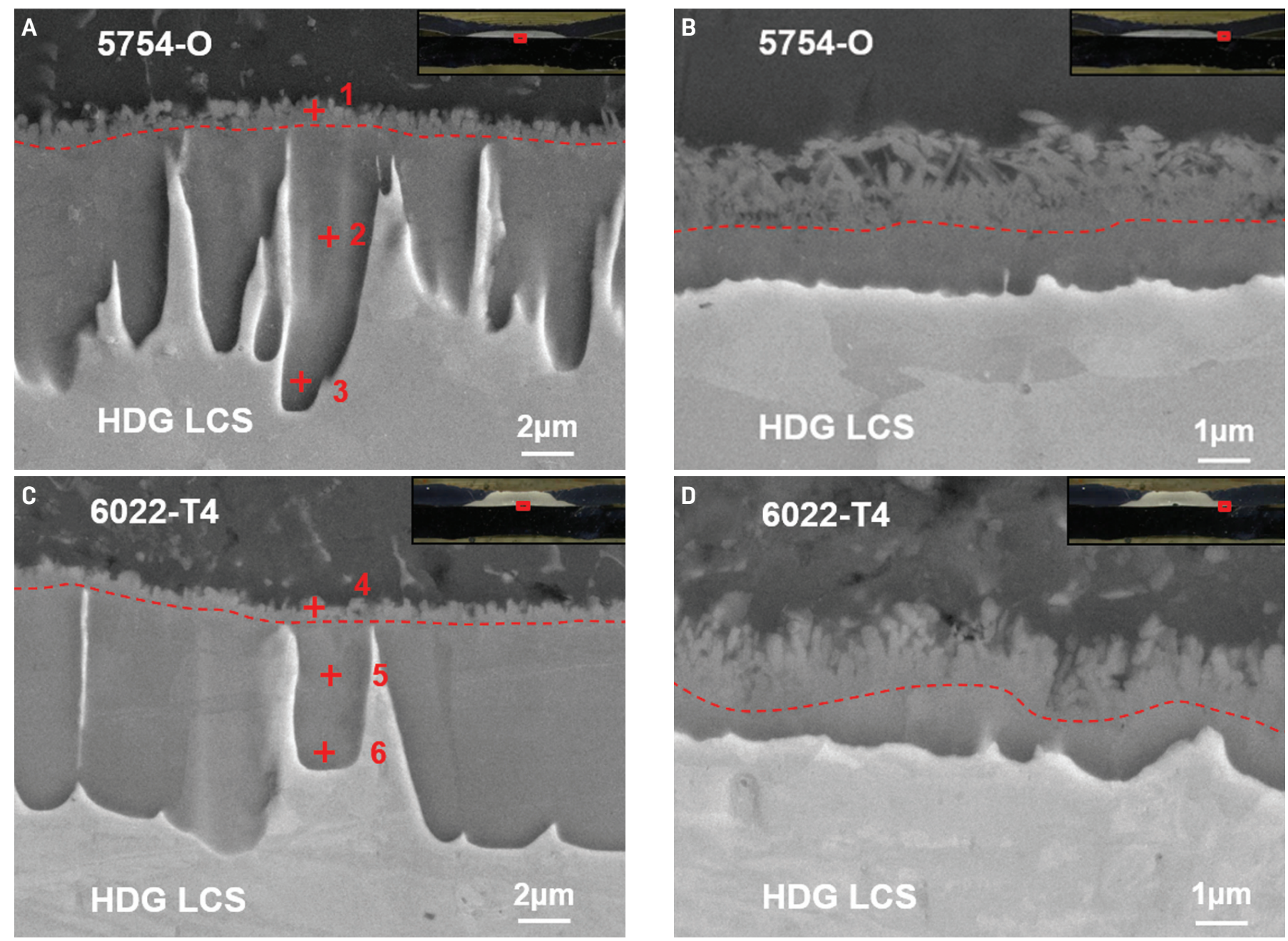

Fig. 12 - IMC morphologies at different locations of the Al-steel welds. A - In the nugget center of the clean 5754-HDG LCS weld; B at the nugget edge of the clean 5754-HDG LCS weld; C - in the nugget center of the clean 6022-HDG LCS weld; D - at the nugget edge of the clean 6022-HDG LCS weld. The red dashed line indicates the boundary between the serrated layer and tongue-like layer.

However, the clean 5754 welds exhibited thicker IMC layers (more than $8 \mu \mathrm{m}$ ) in the center of the nuggets than the 6022 welds and the oxidized 5754 sheets. For the oxidized 5754-HDG LCS welds, expulsion occurred during Stage 1 of the weld schedule, which removed heat and molten aluminum during the welding process. Thus, there was insufficient heat and $\mathrm{Al}$ content for the growth of thick IMC layers.

For the same grade of aluminum sheet, the IMC morphology of clean and oxidized welds was similar. However, the IMC morphologies of the 5754-HDG LCS and 6022HDG LCS welds were different - Fig. 12. In the nugget center, the IMC could be divided into two layers, i.e., a $0.5 \sim 1.0$ $\mu \mathrm{m}$-thick serrated layer adjacent to the aluminum and a 1-7 $\mu \mathrm{m}$-thick tongue-like layer adjacent to the steel side - Fig. $12 \mathrm{~A}$ and $\mathrm{C}$. The tongue-like layer of 6022 welds was flatter and less distinct than that of the 5754 welds. At the edge of the nuggets, however, the IMC layers in the two welds were similar. As shown in Fig. 12B and D, the serrated IMC layer became thicker, and the tongue-like layer became thinner and more continuous.

To identify the segregation of alloying elements, such as $\mathrm{Al}, \mathrm{Fe}, \mathrm{Mg}$, and $\mathrm{Si}$, in the IMC layers of 5754-HDG LCS and
Table 6 - Chemical Composition (wt-\%) of Positions \#1 to \#3 Located in Fig. 15A and B

\begin{tabular}{ccccccc} 
Position & $\mathrm{Al}$ & $\mathrm{Fe}$ & $\mathrm{Si}$ & $\mathrm{Mg}$ & $\mathrm{Zn}$ & 0 \\
\hline 1 & 58.13 & 16.64 & 0.64 & 4.73 & 5.96 & 13.91 \\
2 & 49.94 & 48.49 & 0.17 & 0.00 & 0.03 & 1.37 \\
3 & 19.88 & 3.31 & 0.08 & 7.68 & 66.33 & 2.72 \\
\hline
\end{tabular}

6022-HDG LCS welds, EDS spot analysis was applied to different locations of the IMC layers (refer to the six spots identified in Fig. 12A and $\mathrm{C}$ and the corresponding results in Table 5). In the 5754-HDG LCS weld, from the serrated layer to the tongue-like layer, i.e., from spot \#1 to \#3, the Al-to-Fe ratio varied from 2.81 to 1.81 . For the 6022-HDG LCS weld, the ratio decreased from 3.57 to 1.80 . It should be noted that spots \#1 and \#4 were placed on a thin IMC layer; thus, the measured element content may be influenced by the $\mathrm{Al}$ base metal because the diameter of the EDS spot beam was approximately $1 \mu \mathrm{m}$. Therefore, while the Al-to-Fe ratio of spots \#1 and \#4 are good approximations for comparison, 

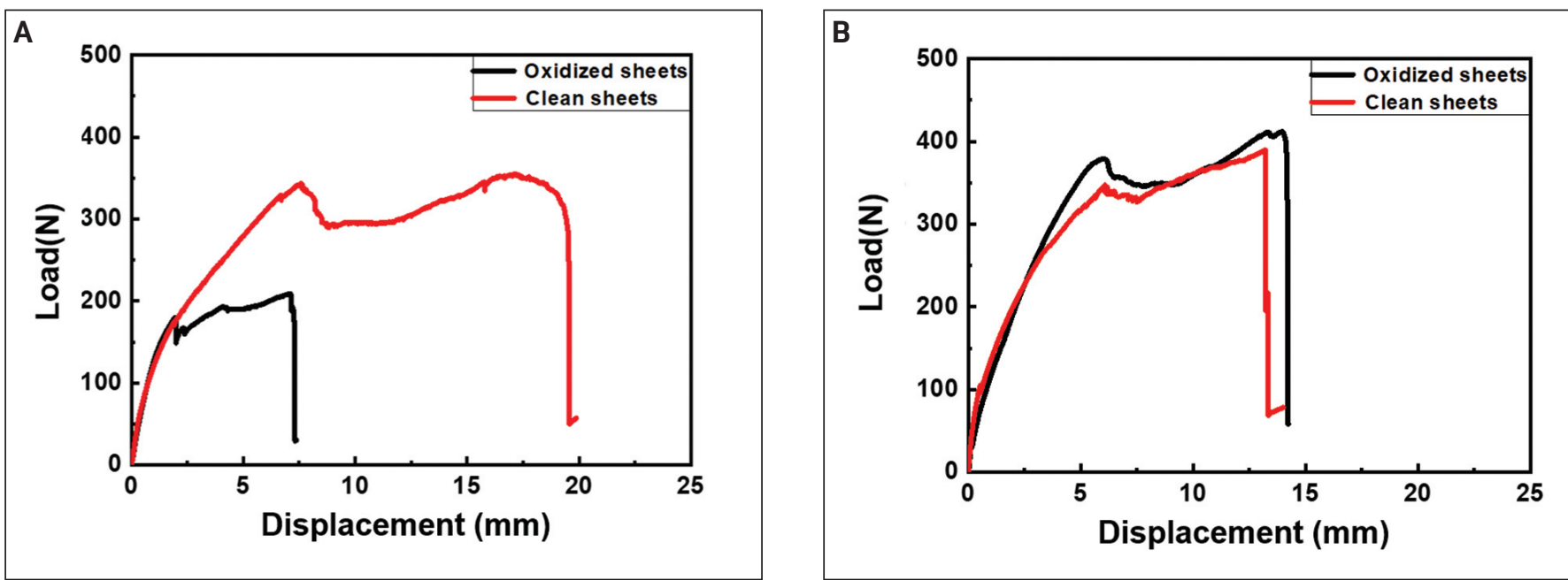

Fig. 13 - Coach peel load-displacement curves of the Al-steel RSW: A - Oxidized 5754-HDG LCS and clean 5754-HDG LCS; B oxidized 6022-HDG LCS and clean 6022-HDG LCS.
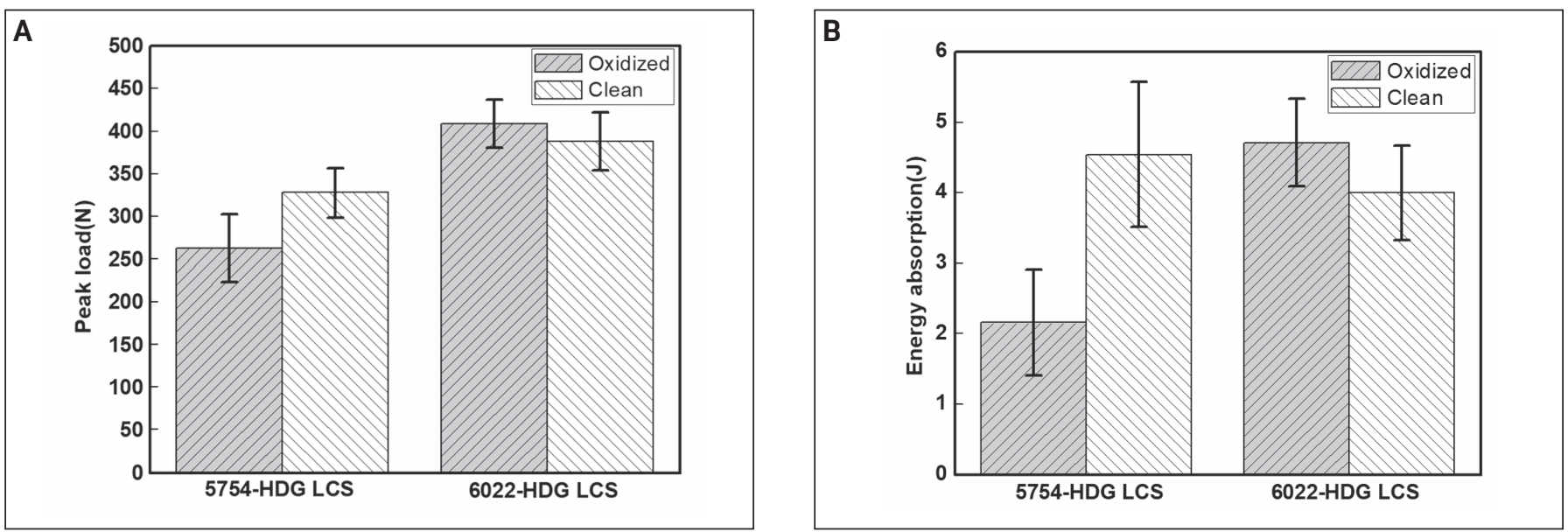

Fig. 14 - Peak load (A) and energy absorption (B) of dissimilar Al-steel welds. Each condition contains seven replicate samples. Error bars represent \pm 1 standard deviation.

the specific values may be an overestimation.

According to the Fe-Al binary phase diagram (Refs. 32, 33), there are several intermetallic compounds, such as $\mathrm{Fe}_{3} \mathrm{Al}$, FeAl, $\mathrm{FeAl}_{2}, \mathrm{Fe}_{2} \mathrm{Al}_{5}$, and $\mathrm{FeAl}_{3}$, that exist in the equilibrium condition. Compared to traditional intermetallic studies (Ref. 9), the dissimilar Al-steel RSW process is very fast because the aluminum nugget is only molten for a second or two and solidification is very directional in nature. Therefore, not all intermetallic compounds can be found in the faying surface. Typically, $\mathrm{Fe}_{2} \mathrm{Al}_{5}$ and $\mathrm{FeAl}_{3}$ are produced during the $\mathrm{Al}$-steel RSW process (Ref. 11). Combined with the EDS spot scan results, the serrated layer and tongue-like layer are estimated to be $\mathrm{FeAl}_{3}$ and $\mathrm{Fe}_{2} \mathrm{Al}_{5}$, respectively.

Although the 5754-HDG LCS and 6022-HDG LCS exhibited similar IMC contents, their morphologies and thicknesses were quite different. The $\mathrm{Fe}_{2} \mathrm{Al}_{5}$ layer in the 5754HDG LCS weld was thick and tongue-like with the IMC layer reaching into the steel substrate; however, the $\mathrm{Fe}_{2} \mathrm{Al}_{5}$ layer in the 6022-HDG LCS weld was thinner and more planar. This can be explained by the different contents of trace elements in the alloys. Trace elements affect the orientation and growth rate of iron-aluminum IMCs (Refs. 9, 10, 34, 35). For 5754-HDG LCS, the content of Mg decreased from spot \#1 to \#3, i.e., from the aluminum side to the steel side, and $\mathrm{Si}$ was not identified since the predominant alloying element in 5754 aluminum is magnesium (Table 5). For 6022-HDG $\mathrm{LCS}$, the content of $\mathrm{Mg}$ also decreased while the Si content increased from spot \#4 to \#6. The growth of $\mathrm{Fe}_{2} \mathrm{Al}_{5}$ is anisotropic preferably along the c-axis (001) of the $\mathrm{Fe}_{2} \mathrm{Al}_{5}$ unit cell because the $\mathrm{Fe}_{2} \mathrm{Al}_{5}$ crystalline lattice contains $30 \%$ of the vacancies along the c-axis (Ref. 34), which offered a rapid diffusion path for $\mathrm{Al}$ atoms into $\mathrm{Fe}_{2} \mathrm{Al}_{5}$. The Si present in the $\mathrm{Fe}_{2} \mathrm{Al}_{5}$ phase (Ref. 35) of 6022-HDG LCS blocked the easy diffusion path along the c-axis. This limited the growth of the tongue-like morphology of the $\mathrm{Fe}_{2} \mathrm{Al}_{5}$ phase in the 6022-HDG LCS. Based on Hwang et al. (Ref. 10), the IMC layer of $\mathrm{Al}$ and Fe developed more thickly as $\mathrm{Mg}$ content increased. A thicker IMC layer forms in the 5754-HDG LCS welds than in 6022-HDG LCS welds when there is no internal expulsion because aluminum alloy 5754 has a richer magnesium content. Although a hotter welding schedule was used to join the 6022-HDG LCS welds, a thinner IMC 


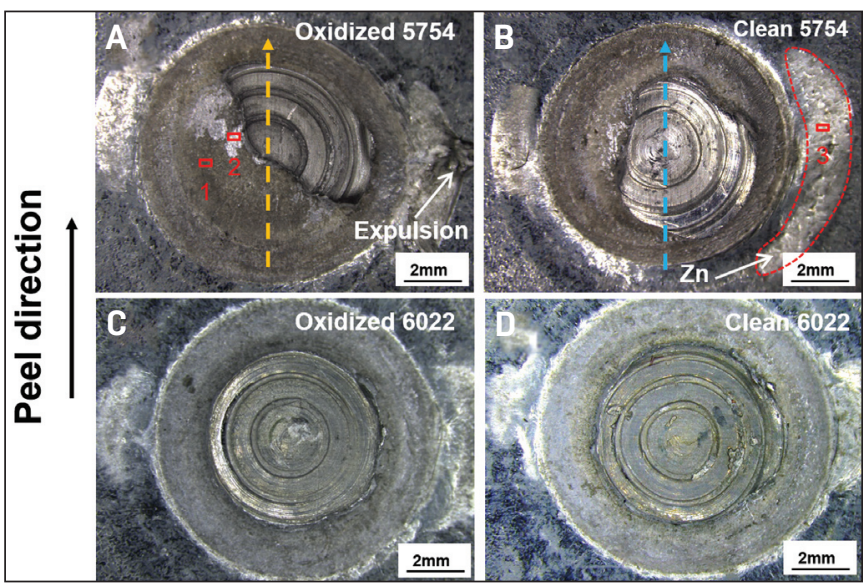

Fig. 15 - Fractographies of Al-steel welds. A - Oxidized 5754HDG LCS; B - clean 5754-HDG LCS; C - oxidized 6022-HDG LCS; $D-$ clean 6022-HDG LCS. The yellow and blue dashed arrows represent the cutting directions for the specimen analysis presented in Figs. 18 and 19, respectively.

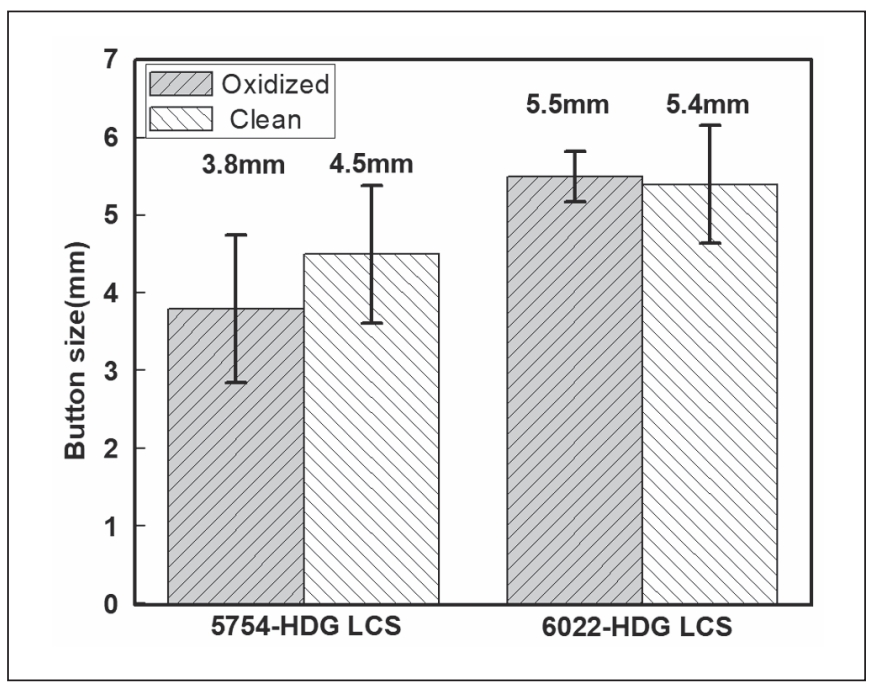

Fig. 16 - Average button size of 5754-HDG LCS and 6022-HDG LCS. Error bars represent \pm 1 standard deviation.

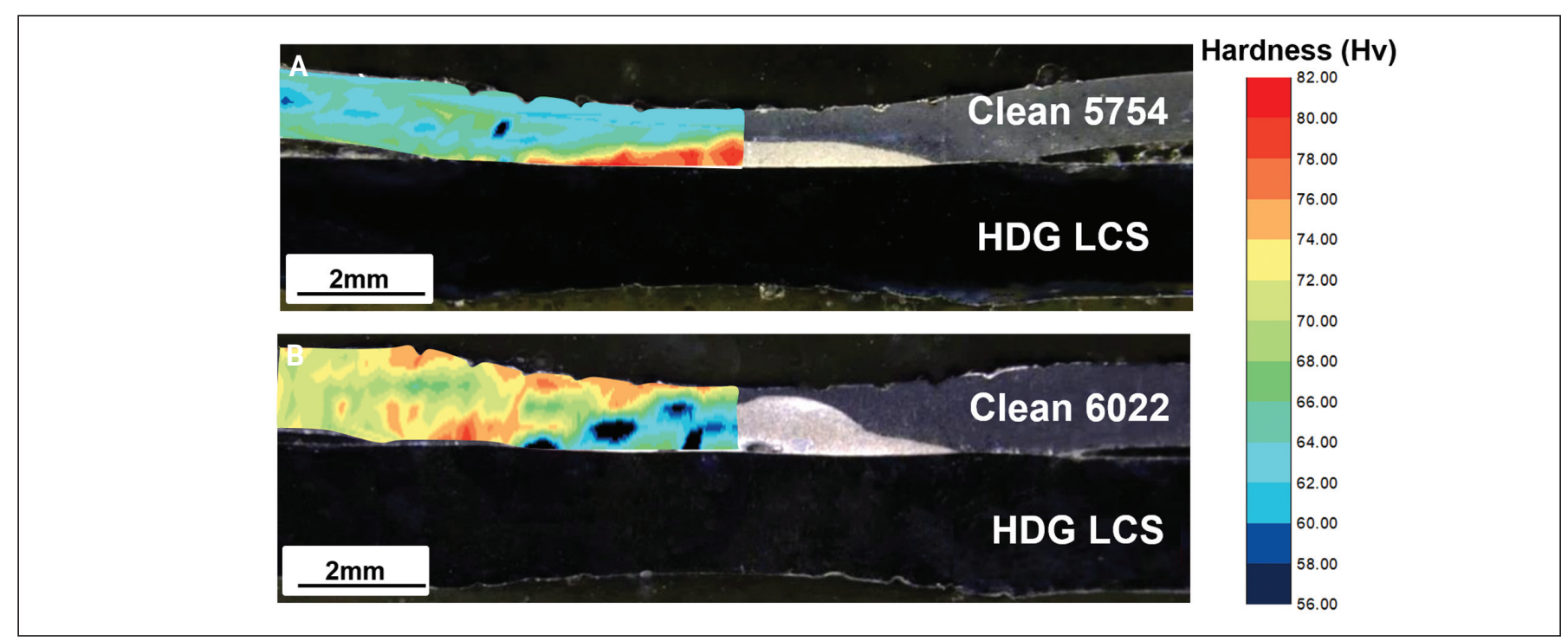

Fig. 17 - Hardness mapping of A - 5754-HDG LCS; B - 6022-HDG LCS.

layer was developed compared to the 5754-HDG LCS welds, indicating that the trace elements play an essential role in IMC growth.

\section{Coach Peel Performance}

Figure 13 presents the coach peel strength and extension relationship of the four cases. The peak load and energy absorption of each case are also compared in Fig. 14. The welds of clean 5754-HDG LCS and both the oxidized and clean 6022-HDG LCS demonstrated better consistency in coach peel performance than the oxidized 5754-HDG LCS welds. Due to internal expulsion, the oxidized 5754 welds had a smaller aluminum nugget size, which reduced the effective load-bearing area and resulted in the low peak load and energy absorption - Fig. 14A. For 6022-HDG LCS, the welds of oxidized 6022 showed a slightly higher load and energy absorption compared to the clean ones - Fig. 14B. This is because the higher contact resistance of the oxidized 6022 sheets helped to produce more heat for nugget growth.

Figure 15 shows fractographies of the Al-steel welds after coach peel tests. The oxidized 5754-HDG LCS welds exhibited partial button fracture, while the clean 5754-HDG LCS and 6022-HDG LCS welds showed full button fracture. In all welds, a circle of lighter metal was observed on the steel sheets surrounding the aluminum button at the faying interface. This lighter metal was identified to be Zn by EDS surface mapping, as shown in Table 6 . Because the Zn coating on the steel sheets has a lower melting point than aluminum, it was readily melted and squeezed out of the weld region early during the welding process. Figure 16 compares the button size of each case. The clean 5754-HDG LCS welds exhibited a larger size on average than the oxidized 5754HDG LCS welds, whereas in the 6022-HDG LCS welds, the oxidized and clean surfaces produced approximately the same button sizes. 


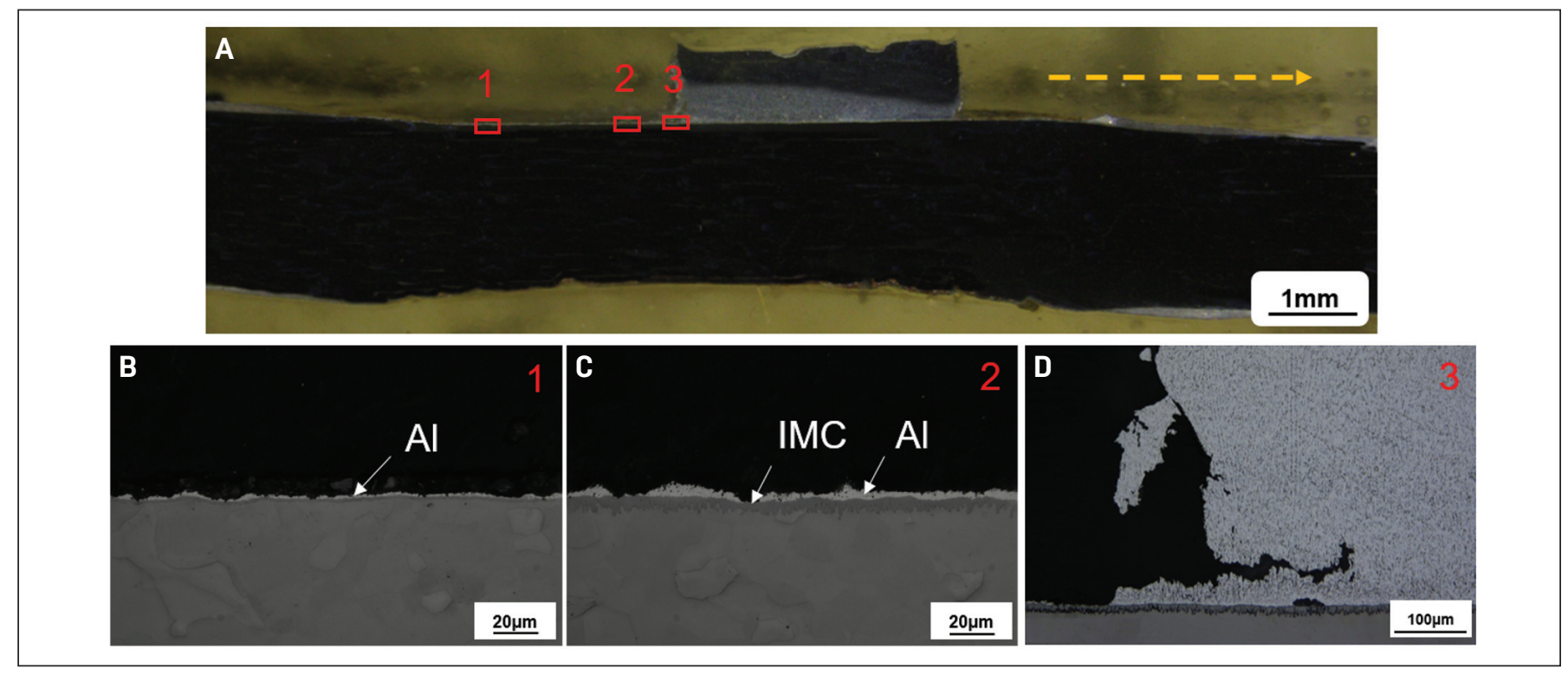

Fig. 18 - Crack propagation of the oxidized 5754-HDG LCS weld.

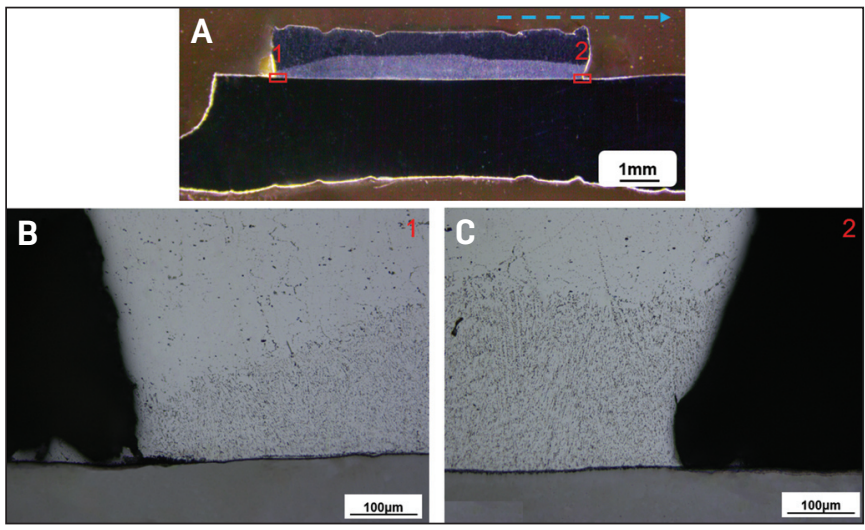

Fig. 19 - Crack propagation of the clean 5754-HDG LCS weld.

To understand the fracture mechanism, hardness mapping of the clean welds of 5754-HDG LCS and 6022-HDG LCS was performed. A microhardness test of HV0.05 was conducted on a Buehler Wilson VH1102 hardness tester with 0.2-mm pitch and 10-s dell time. As shown in Fig. 17, the aluminum nugget of 5754 was harder than the base material because of the formation of iron-rich compounds in the nugget. However, for 6022, since the base material is in a T4 natural aging state, thermal cycles during the RSW process cause the dissolution and coarsening of strengthening precipitates in the nugget. As a result, the nugget of 6022 became softer - Fig. 17B. For both welds, the hardness distribution showed an abrupt change at the edge of the nugget, which made the nugget edge more susceptible to crack propagation.

To compare the fracture path of the oxidized and clean 5754-HDG LCS welds, the fractured specimens were evaluated metallographically in Figs. 18 and 19. The cutting direction was along the peel direction, as shown by the yellow dotted line in Fig. 15A and blue dotted line in Fig. 15B.

According to Fig. 18B, in the oxidized 5754 weld, the crack propagated through the aluminum nugget parallel to the faying interface where the IMC was thin. As the IMC grew thicker, the crack propagated preferably along the aluminum or within the IMC. The crack deflected upward in the middle of the aluminum nugget, where pore defects were located - Fig. 18D.

In the clean 5754 welds, because there were fewer oxide film defects and a thin IMC layer at the nugget edge, it was difficult for cracks to propagate along the faying surface continuously. Therefore, the crack propagated upward as it entered the nugget, as shown in Fig. 19B. On the other hand, the 5754-HDG LCS had a harder nugget after welding, as shown in Fig. 17A. The crack went upward to the softer region outside the nugget to form a larger button.

To identify the elements on the fracture surface, EDS mapping tests were performed (refer to Table 6), which provides the EDS results of positions 1 and 2 in Fig. 15A, and position 3 in Fig. 15B. In regions of interfacial failure of the oxidized 5754-HDG LCS weld, most regions appeared dark (Fig. 20A) and were evaluated to have a higher oxygen content (refer to Table 6). These dark regions corresponded to oxide films within the aluminum. In contrast, the light area located in Fig. 15A exhibited a cleavage surface (Fig. 20B), which was rich in $\mathrm{Al}$ and $\mathrm{Fe}$ and identified to be part of the IMC layer. Thus, during coach peel tests of the oxidized 5754-HDG LCS, the crack preferentially propagated along the oxide film layer in the aluminum. In the absence of oxide film, the crack propagated within the IMC layer. The crack ultimately deflected upward in a region with pores defects.

The crack paths in oxidized and clean 5754-HDG LCS welds are summarized in Fig. 21. Cracks initiated at the edge of the weld in the notch slit region as shown in Fig. 21A. The shape of the notch root angle between the aluminum and steel sheets affects the application of applied load to the notch slit region and the initiation of cracking with sharper notch roots, producing more stress concentration. At the edge of the aluminum weld nugget, cracks preferentially propagated along oxide film defects if they were present or in the thick IMC layer, as shown in Fig. 21B. When the crack propagated to a re- 

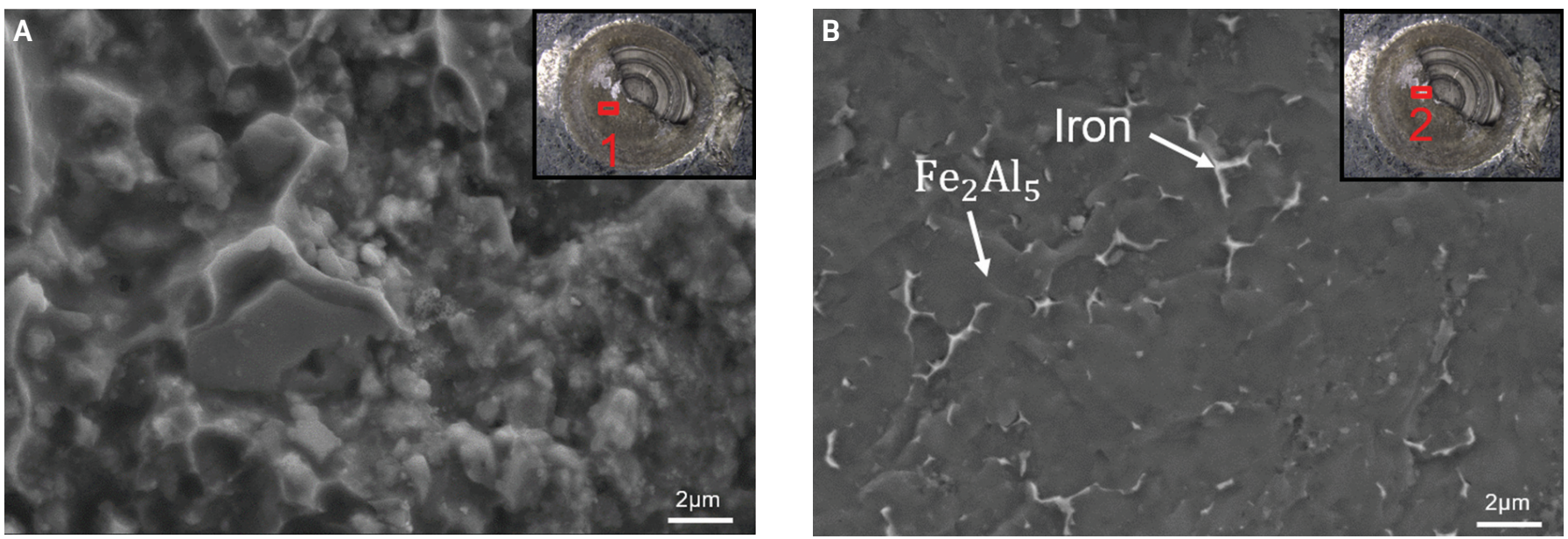

Fig. 20 - Fractographies of A - Position \#1; B - \#2 located in Fig. 15A.
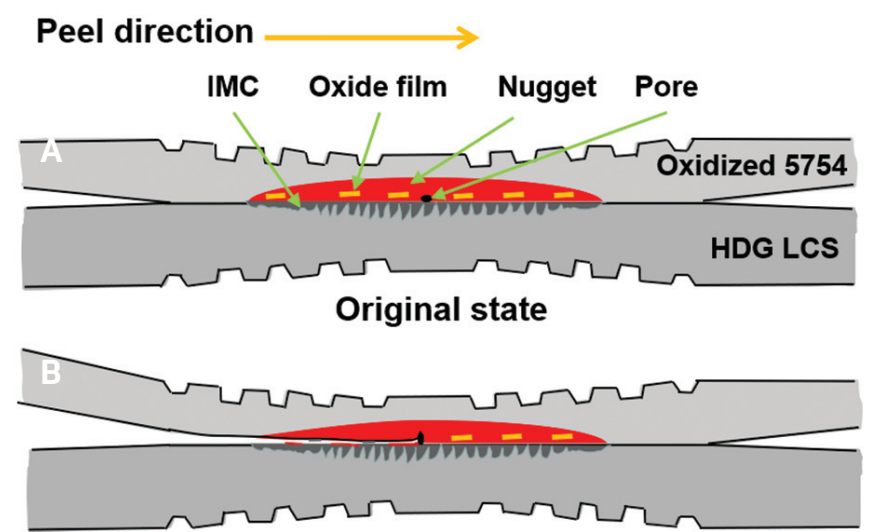

Fracture propagates along oxide film defects

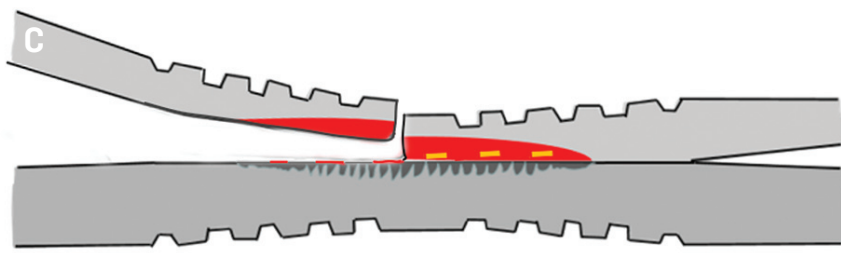

Tear in thickness direction

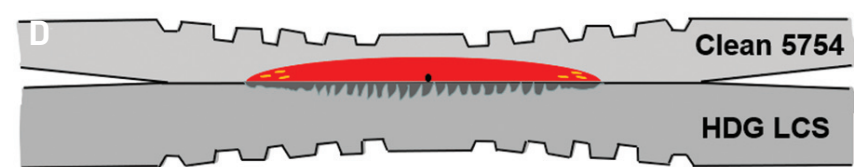

Original state

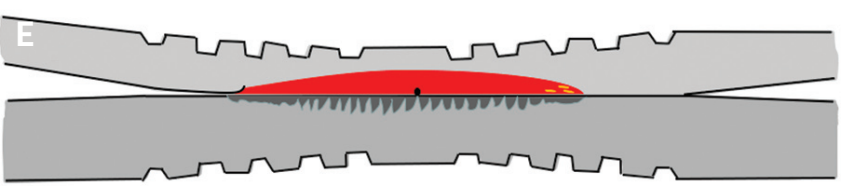

Fracture at the nugget edge

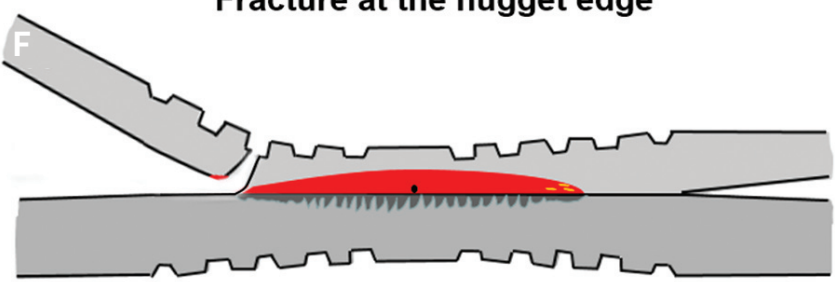

Tear in thickness direction

Fig. 21 - Crack path of A-C - oxidized 5754-HDG LCS weld; D-F - clean 5754-HDG LCS weld.

gion of the aluminum that was sufficiently thin and no oxide film was present, the crack deflected upward through the aluminum where pores were located (Fig. 21C), forming a partial button fracture mode, as shown in Fig. 15A.

In the absence of oxide films, welds would typically fracture at one of the MRD ring indentations where the aluminum was thinner. For the clean 5754-HDG LCS welds without oxide films and with the large nugget size, cracking initiated in the notch slit region and propagated to the nugget edge where it was deflected upward to a softer area - Fig. 21D and E. The crack continued to propagate upward through the aluminum to the indentation made by the third ring of the MRD electrode, as shown in Fig. 21F. Following this, the crack followed the third ring indentation circumferentially around the weld nugget to form a button pull-out fracture.

This crack propagation behavior was also observed in the oxidized and clean 6022-HDG LCS welds, but to a lesser degree, as there were fewer oxide film defects at the nugget edge. Thus, in the oxidized and clean 6022-HDG LCS welds, the crack deflected upward through the aluminum sooner to form a larger weld button following fracture.

\section{Conclusion}

This body of work compared dissimilar resistance spot welds of 5754-LCS and 6022-LCS made using MRD electrodes and multiple solidification weld schedules. The effect of aluminum sheet contact resistance on weld macrostruc- 
ture, microstructural defects, IMC characteristics, and coach peel performance was investigated. The conclusions drawn from this study are as follows:

1) Trace elements were observed to have an essential role in the IMC growth. In the 6022-HDG LCS welds, the relatively large amount of $\mathrm{Si}$ inhibited the diffusion of iron and resultant formation of $\mathrm{Fe}_{2} \mathrm{Al}_{5}$, which produced a relatively planar and thin IMC layer. However, in the 5754-HDG LCS welds, the rich $\mathrm{Mg}$ content promoted the growth of the $\mathrm{Fe}_{2} \mathrm{Al}_{5}$ phase, resulting in a less planar and thicker IMC layer.

2) AA5754-O developed a higher contact resistance over the aging period when exposed to ambient conditions. The higher contact resistance generated excessive heat at the faying interface during RSW and caused internal expulsion, which produced smaller aluminum nuggets. However, AA6022-T4 did not exhibit the same increase in contact resistance under the same exposure conditions, which may have contributed to the formation of a larger aluminum nugget.

3) The contact resistances relate to the presence and potential growth of nascent oxide layers on the aluminum sheet. In some instances, such as with the high contact resistance 5754-HDG LCS welds, the oxide layer was persistent in the solidified weld structure above the faying interface but was not present in lower contact resistance Al-steel welds comprised of either 5754 or 6022.

4) The oxide film defects served as low-energy crack propagation sites during mechanical testing. Thus, oxide film defects in combination with smaller weld nugget diameters in the oxidized 5754-HDG LCS welds decreased the load-carrying capacity. This behavior was not observed in cleaned 5754 or 6022 HDG LCS welds.

5) Sheet metal is likely to be in an unclean and variable condition in a production environment as surface cleaning is a time-consuming and costly addition to the production process. It is necessary to develop the Al-steel RSW process for aluminum alloys, such as 5754, which exhibit a more robust oxide layer to eliminate required cleaning steps.

\section{Acknowledgments}

The authors would like to acknowledge the financial support of the GM Research and Development Center and the National Natural Science Foundation of China (Grant Nos. U1564204, U1764251, and 51322504). The authors also thank Chad Clark (Fusion Welding Solutions) and David Sigler (General Motors, retired) for their welding expertise and valuable discussions.

\section{References}

1. Lei, H., Li, Y., Carlson, B. E., and Lin, Z. 2016. Microstructure and mechanical performance of cold metal transfer spot joints of AA6061-T6 to galvanized DP590 using edge plug welding mode. Journal of Manufacturing Science and Engineering, Transactions 138(7): 071009. DOI: 10.1115/1.4032082

2. Wan, Z., Wang, H.-P., Chen, N., Wang, M., and Carlson, B. E. 2017. Characterization of intermetallic compound at the interfaces of Al-steel resistance spot welds. Journal of Materials Processing
Technology 242: 12-23. DOI: 10.1016/j.jmatprotec.2016.11.017

3. Sigler, D. R., Carlson, B. E., and Allvar, M. 2016. Robotic simulation of spot welding aluminum stack-ups and steel stack-ups for the cadillac CT6 MY16 using a single gun, single electrode solution. Conference Proceedings of AWS Sheet Metal Welding Conference XVII, Livonia, Mich., October 19, 20, pp. 1-20.

4. Sigler, D. R., and Carlson, B. E. 2018. Impediments to developing resistance spot welding processes for joining aluminum to steel. Conference Proceedings of AWS Sheet Metal Welding Conference XVIII, pp. 1-18.

5. Rao, H. M., Kang, J., Shia, L., Sigler, D. R., and Carlson, B. E. 2018. Effect of specimen configuration on fatigue properties of dissimilar aluminum to steel resistance spot welds. International Journal of Fatigue 116: 13-21. DOI: 10.1016/j.ijfatigue.2018.06.009

6. Chen, N., Wang, H.-P., Carlson, B. E., Sigler, D. R., and Wang, M. 2017. Fracture mechanisms of $\mathrm{Al} /$ steel resistance spot welds in lap shear test. Journal of Materials Processing Technology 243: 347-354. DOI: 10.1016/j.jmatprotec.2016.12.015

7. Miyamoto, K., Nakagawa, S., Sugi, C., Sakurai, H., and Hirose, A. 2009. Dissimilar joining of aluminum alloy and steel by resistance spot welding. SAW International Journal of Materials and Manufacturing 2: 58-67. DOI: 10.4271/2009-01-0034

8. Chen, N., Wang, M., Wang, H.-P., Wan, Z., and Carlson, B. E. 2018. Microstructural and mechanical evolution of $\mathrm{Al} /$ steel interface with $\mathrm{Fe}_{2} \mathrm{Al}_{5}$ growth in resistance spot welding of aluminum to steel. Journal of Manufacturing Processes 34: 424-434. DOI: 10.1016/j.jmatprotec.2016.12.015

9. Yin, F.-C., Zhao, M.-X., Liu, Y.-X., Han, W., and Li, Z. 2013. Effect of $\mathrm{Si}$ on growth kinetics of intermetallic compounds during reaction between solid iron and molten aluminum. Trans. Nonferrous Met. Soc, China 23: 556-561. DOI: 10.1016/S1003-6326(13)62499-1

10. Hwang, I. H., Watanabe, T., and Doi, Y. 2007. Dissimilar metal welding of steel to Al-Mg alloy by spot resistance welding. Advanced Materials Research 15-17, pp. 81-386. DOI: 10.4028/ www.scientific.net/AMR.15-17.381

11. Shi, L., Kang, J., Shalchi-Amirkhiz, B., Sigler, D. R., Haselhuhn, A. S., and Carlson, B. E. 2019. Effect of coating type on microstructure and mechanical behavior of resistance spot welds of thin X626 aluminum sheet to low carbon steel. Journal of Materials Processing Tech. 264: 438-447. DOI: 10.1016/j.jmatprotec.2018.09.025

12. Lesemann, M., Bröckerhoff, M., and Urban, P. 2008. The prospects of multi-material design for a compact-class front section. ATZautotechnology 8(7): 16-20. DOI: 10.1007/BF03247063

13. Ma, Y.-M., Lou, M., Li, Y.-B., and Lin, Z.-Q. 2018. Effect of rivet and die on self-piercing rivetablity of AA6061-T6 and mild steel CR4 of different gauges. Journal of Material Processing Tech. 251: 282-294. DOI: 10.1016/j.jmatprotec.2017.08.020

14. Wang, Z., Wang, H.-P., Wang, M., Carlson, B. E., and Sigler, D. R. 2016. Numerical simulation of resistance spot welding of $\mathrm{Al}$ to zinc-coated steel with improved representation of contact interactions. International Journal of Heat and Mass Transfer 101: 749-763. DOI: 10.1016/j.ijheatmasstransfer.2016.05.023

15. Deng, L., Li, Y.-B., Carlson, B. E., and Sigler, D. R. 2018. Effect of electrode surface topography on aluminum resistance spot welding. Welding Journal 98(4): 120-s to 132-s.

16. Zhang, H., and Senkara, J. 2006. Resistance Welding: Fundamentals and Applications. CRC Press, p. 39. DOI: 10.29391/ 2018.97.011

17. Li, Z., Hao, C., Zhang, J., and Zhang, H. 2017. Effects of sheet surface conditions on electrode life in resistance welding aluminum. Welding Journal 97(4): 81-s to 89-s.

18. Al Naimi, I. K., and Al Saadi, M. H. 2015. Influence of surface pretreatment in resistance spot welding of aluminum AA105. Production \& Manufacturing Research: An Open Access Journal 3(1): 185-200. DOI: 10.1080/21693277.2015.1030795

19. Arrington Jr., S. E. 1995. Twisting Electrodes Improve Tip Life and Weld Quality on Resistance Spot Welded Aluminum Sheet. 
Aluminum Applications for Automotive Design. SAE Paper 950717. DOI: $10.4271 / 950717$

20. Sigler, D. R., Carlson, B. E., and Karagoulis, M. J. 2017. Welding Electrode Cutting Tool and Method of Using the Same, U.S. Patent Application 20170225262.

21. Sigler, D. R., Schroth, J. G., Karagoulis, M. J., and Zuo, D. 2010. New electrode weld face geometries for spot welding aluminum. Proceedings of the AWS Sheet Metal Welding Conference XIV, Livonia, Mich., May 11-14, 2010, pp. 1-19.

22. Shi, L., Kang, J., Sigler, D. R., Haselhuhn, A. S., and Carlson, B. E. 2019. Microstructure and fatigue behavior of novel multi-ring domed resistance spot welds for thin X626-T4 aluminum sheets. International Journal of Fatigue 119: 185-194. DOI: 10.1016/ j.ijfatigue.2018.08.022

23. Haselhuhn, A. S., Sigler, D. R., and Carlson B. E. 2018. Static and dynamic mechanical performance of aluminum-steel resistance spot welds. Conference Proceedings of the AWS Sheet Metal Welding Conference XVIII, pp. 1-34.

24. Chen, C., Kong, L., Wang, M., Haselhuhn, A. S., Sigler, D. R., Wang, H.-P., and Carlson, B. E. 2019. The robustness of Al-steel resistance spot welding process. Journal of Manufacturing Processes 43A: 300-310. DOI: 10.1016/j.jmapro.2019.02.030

25. Haselhuhn, A. S., Chen, C., Sigler, D. R., and Carlson, B. E. 2018. Robustness of aluminum-steel resistance spot welds to production conditions. Conference Proceedings of the AWS Sheet Metal Welding Conference XVIII, pp. 1-20.

26. Sigler, D. R., and Karagoulis, M. J. 2014. Cutting Tool for Forming and Reforming Welding Electrodes with Contoured Faces, U.S. Patent 8,833,215.

27. Sigler, D. R., Carlson, B. E., and Karagoulis, M. J. 2017. Multi-stage Resistance Spot Welding Method for Workpiece Stack-up Having Adjacent Steel and Aluminum Workpieces, U.S. Patent Application 20170106466.

28. Sigler, D. R., Carlson, B. E., Myasnikova, Y., and Karagoulis, M. J. 2015. Multi-step Direct Welding of an Aluminum-Based Workpiece to a Steel Workpiece, U.S. Patent Application 20150053655.
29. Westengen, H. 2001. Magnesium: Alloying, in Encyclopedia of Materials: Science and Technology, K. H. J. Buschow et al., Editors. Elsevier: Oxford. p. 4739-4743. DOI: 10.1016/B0-08043152-6/00825-1

30. Wang, Y. R., Mo, Z. H., Feng, J. C., and Zhang, Z. D. 2007. Effect of welding time on microstructure and tensile shear load in resistance spot welded joints of AZ31 Mg alloy. Science and Technology of Welding and Joining 12 (8): 671-676. DOI: 10.1179/ 174329307X238380

31. Huang, W., and Huang, J. 2004. Aluminum and Aluminum Alloy Welding Guide. Hunan Science and Technology Press, p. 86.

32. ASM International. 1992. Metals Handbook $10^{\text {th }} \mathrm{Ed}$. Vol. 63. DOI: 10.1016/S0921-5093(02)00053-9

33. Shigeaki Kobayashi, T. Y. 2002. Control of intermetallic compound layers at interface between steel and aluminum by diffusion-treatment. Materials Science and Engineering A 338: 44-53.

34. Heumann, T., and Dittrich, N. 1959. Structure character of the Fe2Al5 intermetallic compound in hot dip aluminizing process. Z. Metalk 50: 617-623.

35. Xia, H., Tao, W., Li, L., Tan, C., Zhang, K., and Ma, N. 2020. Effect of laser beam models on laser welding-brazing Al to steel. Optics \& Laser Technology 122: 105845. DOI: 10.1016/j.optlastec.2019.105845

SHANQING HU, YUNWU MA, YONGBING LI (yongbinglee@ sjtu.edu.cn), and ZHONGQIN LIN are with the Shanghai Key Laboratory of Digital Manufacture for Thin-Walled Structures, School of Mechanical Engineering, Shanghai Jiao Tong University, Shanghai, China. HU, LI, and LIN are also with the State Key Laboratory of Mechanical System and Vibration, School of Mechanical Engineering, Shanghai Jiao Tong University, Shanghai, China. AMBERLEE S. HASELHUHN and BLAIR E. CARLSON are with Manufacturing Systems Research Lab, General Motors Global R\&D, Warren, Mich.

\section{Welding Journal Now Publishing Direct Object Identifier (DOI) Numbers}

\section{Dear members of the welding research community,}

Note that in each issue of the Welding Journal Research Supplement, we are including Direct Object Identifier (DOI) numbers with each of the papers published in print and online. A direct object identifier is a unique alphanumeric string assigned by a registration agency (we are using Crossref.org) to identify content and provide a persistent link to its location on the Internet. Our decision to begin assigning a DOI for each paper comes directly from a request by the research community.

As part of our obligation to Crossref.org, we are asked to provide DOI numbers, when available, in the references section of papers. So, if you have submitted a paper to the Welding Journal or are planning on submitting a paper, we ask that you update your references to include DOI numbers whenever possible.

Thank you.

Annette Alonso

Publisher, Welding Journal 